\title{
SIRT1 protects against emphysema via FOXO3-mediated reduction of premature senescence in mice
}

\author{
Hongwei Yao, ${ }^{1}$ Sangwoon Chung, ${ }^{1}$ Jae-woong Hwang, ${ }^{1}$ Saravanan Rajendrasozhan, ${ }^{1}$ \\ Isaac K. Sundar, ${ }^{1}$ David A. Dean, ${ }^{2}$ Michael W. McBurney, ${ }^{3}$ Leonard Guarente, ${ }^{4}$ Wei Gu, ${ }^{5}$ \\ Mikko Rönty, ${ }^{6}$ Vuokko L. Kinnula, ${ }^{6}$ and Irfan Rahman ${ }^{1}$
}

\begin{abstract}
'Department of Environmental Medicine, Lung Biology and Disease Program, and 2Department of Pediatrics, University of Rochester Medical Center Rochester, New York, USA. ${ }^{3}$ Center for Cancer Therapeutics, Ottawa Hospital Research Institute, Ottawa, Ontario, Canada. ${ }^{4}$ Department of Biology, Massachusetts Institute of Technology, Cambridge, Massachusetts, USA. Institute of Cancer Genetics and Department of Pathology, College of Physician and Surgeons, Columbia University, New York, New York, USA. ${ }^{6}$ Departments of Pathology and Medicine, University of Helsinki and Helsinki University Central Hospital, Helsinki, Finland.
\end{abstract}

\begin{abstract}
Chronic obstructive pulmonary disease/emphysema (COPD/emphysema) is characterized by chronic inflam-

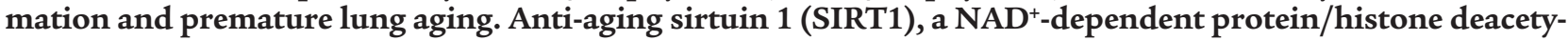
lase, is reduced in lungs of patients with COPD. However, the molecular signals underlying the premature aging in lungs, and whether SIRT1 protects against cellular senescence and various pathophysiological alterations in emphysema, remain unknown. Here, we showed increased cellular senescence in lungs of COPD patients. SIRT1 activation by both genetic overexpression and a selective pharmacological activator, SRT1720, attenuated stress-induced premature cellular senescence and protected against emphysema induced by cigarette smoke and elastase in mice. Ablation of Sirt1 in airway epithelium, but not in myeloid cells, aggravated airspace enlargement, impaired lung function, and reduced exercise tolerance. These effects were due to the ability of SIRT1 to deacetylate the FOXO3 transcription factor, since Foxo3 deficiency diminished the protective effect of SRT1720 on cellular senescence and emphysematous changes. Inhibition of lung inflammation by an NF- $\mathrm{B} / \mathrm{IKK} 2$ inhibitor did not have any beneficial effect on emphysema. Thus, SIRT1 protects against emphysema through FOXO3-mediated reduction of cellular senescence, independently of inflammation. Activation of SIRT1 may be an attractive therapeutic strategy in COPD/emphysema.
\end{abstract}

\section{Introduction}

Chronic obstructive pulmonary disease (COPD) is characterized by destruction of the alveolar wall, decline in lung function, and chronic inflammatory response (per Global Initiative for COPD [GOLD] guidelines). It was recently thought that pulmonary emphysema (one of the major components of COPD) develops as a result of accelerated premature aging of the lung due to cellular senescence and epigenomic instability caused by cigarette smoke (CS) and noxious gases (1-3). Current therapies for COPD are symptomatic and have no effect on lung cellular maintenance, which suggests the involvement of other mechanisms in pathogenesis of COPD $(4,5)$.

Sirtuin 1 (SIRT1) plays an important role in many pathophysiological processes, including cellular senescence/aging, inflammation, stress resistance, apoptosis/proliferation, and autoimmunity (6-8). SIRT1 requires $\mathrm{NAD}^{+}$as a cofactor and functions by deacetylating intracellular targets, including transcription factors, signaling molecules, and chromatin histones (9-12). SIRT1 also regulates a stress-response transcription factor, FOXO3, thereby modulating cellular senescence/aging, skeletal muscle function, cardiovascular homeostasis, and human longevity $(11,13-16)$. We and others have recently shown that SIRT1, an antiaging protein, is reduced in lungs of patients with $\operatorname{COPD}(17,18)$. Emerging evidence suggests the involvement of lung cellular senescence in vitro

Conflict of interest: The authors have declared that no conflict of interest exists. Citation for this article: J Clin Invest. 2012;122(6):2032-2045. doi:10.1172/JCI60132. and in vivo in response to CS $(3,19-25)$. However, the molecular mechanism of CS-induced cellular senescence, and whether SIRT1 protects against stress-induced premature senescence (SIPS) and various pathophysiological changes in COPD, remain unknown. We hypothesized that SIRT1 protects against SIPS through the regulation of $\mathrm{FOXO} 3$, thereby attenuating emphysema. Using genetic and pharmacological approaches, we showed here the molecular mechanism of CS-induced cellular senescence via a SIRT1-FOXO3 axis, and a seminal role of SIRT1 in protection against airspace enlargement and lung function decline (characteristic features of COPD).

\section{Results}

SIRT1 protects against pulmonary emphysema. SIRT1 level was decreased in mouse lung exposed to CS and elastase (Supplemental Figure 1, A and B; supplemental material available online with this article; doi:10.1172/JCI60132DS1). To determine the role of SIRT1 in the development of pulmonary emphysema, we exposed Sirt1-deficient heterozygous/haploinsufficient (Sirt1 ${ }^{+-} ; 129 / \mathrm{SvJ}$ background) (26) and Sirt1-overexpressing/transgenic (Sirt1 Tg; C57BL/6J×129/SvJ background) mice (27), as well as their WT littermates, to CS or elastase. Lung SIRT1 protein level was decreased in $\mathrm{Sirt1}^{+/-}$mice, whereas it was increased in Sirt1 Tg mice compared with their WT littermates (Supplemental Figure 1C). Sirt1 ${ }^{+/-}$mice showed a spontaneous airspace enlargement compared with WT mice only after 1 year of age, which is consistent with an agedependent reduction of lung SIRT1 level (Supplemental Figure 
A
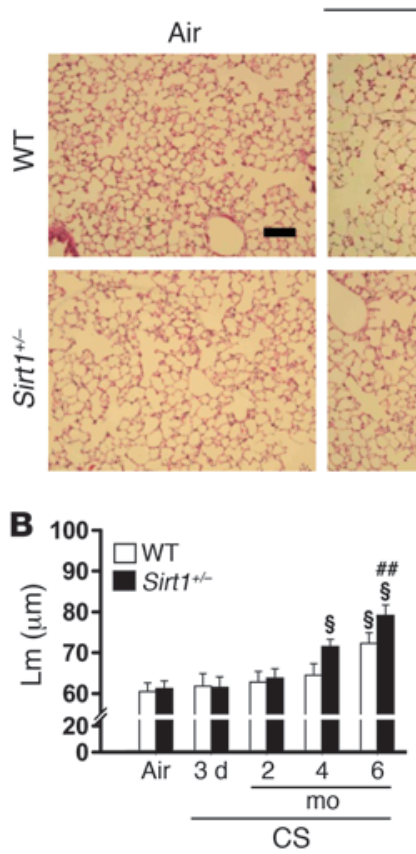

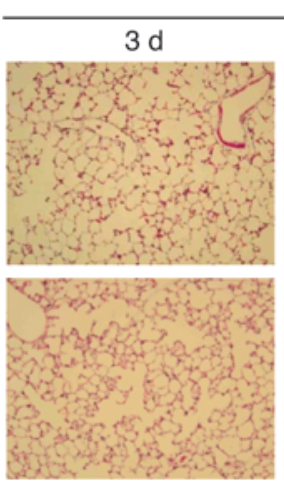

c
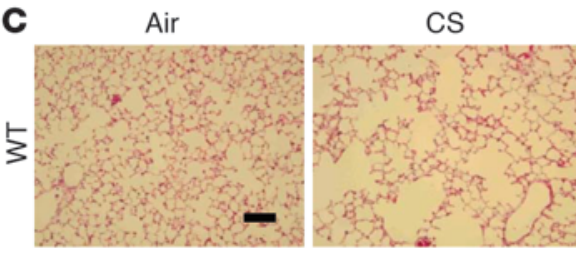

$\mathbf{F}$
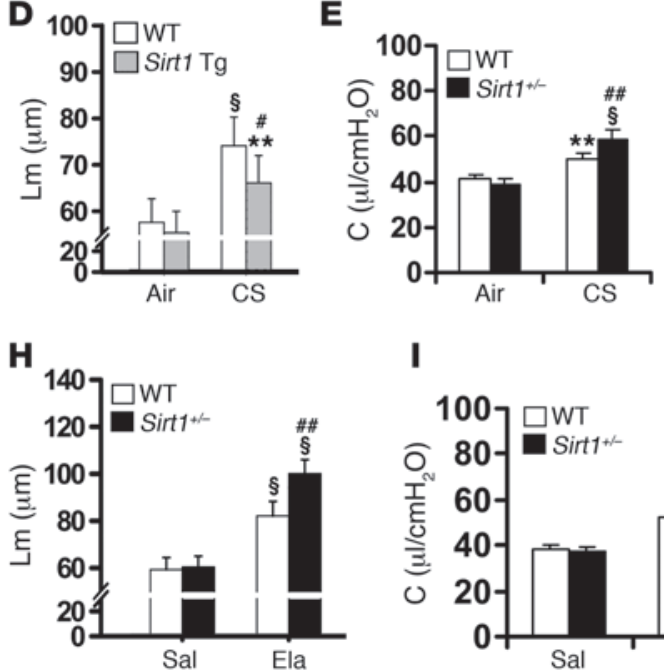

I

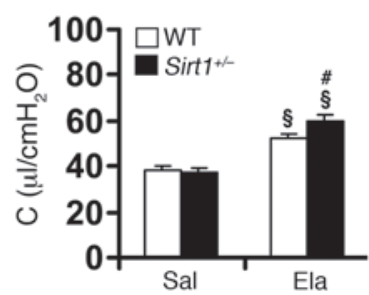

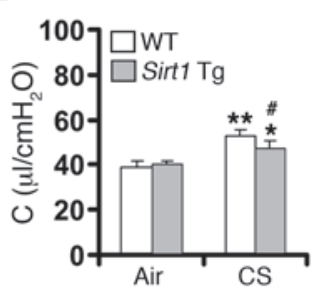

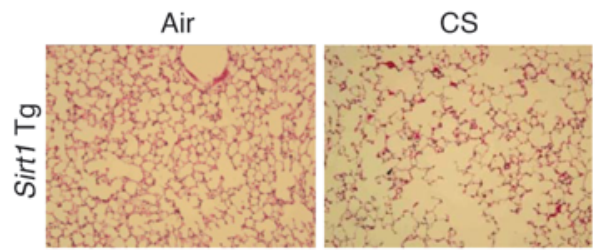

CS

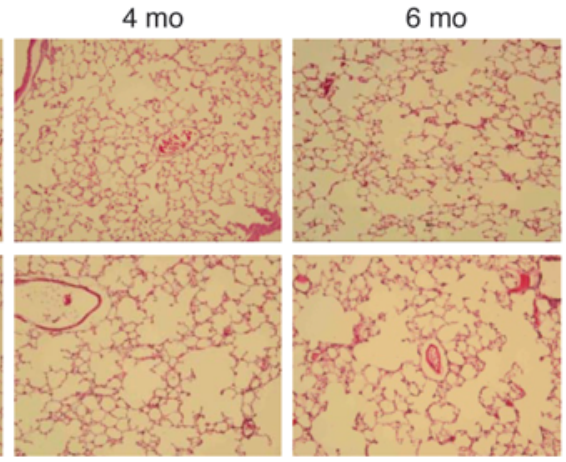

G
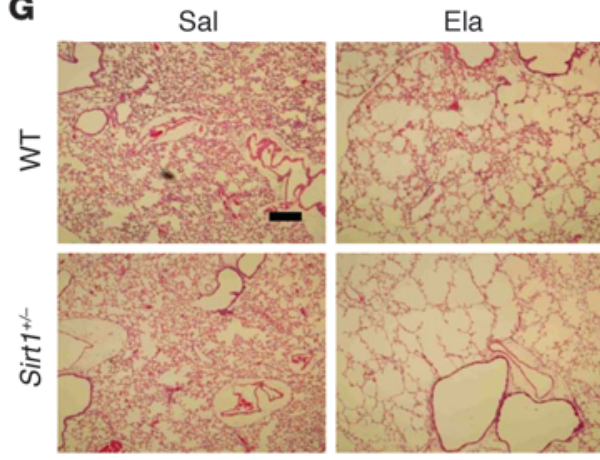

Figure 1

SIRT1 protects against airspace enlargement and increased lung compliance in emphysematous mice. (A-D) Sirt1+/- mice were susceptible to developing airspace enlargement (A and B), whereas overexpression of Sirt1 (i.e., Sirt1 Tg mice) attenuated the increased Lm of airspace in response to 6 months of CS exposure (C and $\mathbf{D})$. (E and $\mathbf{F})$ Lung compliance (C) was increased in Sirt1+/- mice compared with WT littermates in response to 6 months of CS exposure $(\mathbf{E})$, which was attenuated by Sirt1 overexpression $(\mathbf{F})$. (G and $\mathbf{H})$ Sirt1 deficiency increased the airspace enlargement induced by intratracheal injection of elastase (Ela). Sal, saline. (I) Lung compliance was increased in Sirt $1^{+/-}$mice compared with WT littermates after elastase exposure. H\&E-stained images are representative of experiments from 3 separate mice. Original magnification, $\times 100$. Scale bars: $100 \mu \mathrm{m} . n=3-4$ per group. ${ }^{\star} P<0.05$, ${ }^{\star \star} P<0.01, \S P<0.001$ versus air or saline; $\# P<0.05$, \#\#P<0.01 versus WT.

2, A-C). CS exposure for 6 months induced a modest airspace enlargement in WT mice, whereas Sirt $1^{+/-}$mice started to exhibit airspace enlargement after just 4 months of CS exposure, which was augmented at 6 months (Figure 1, A and B). Overexpression of Sirt1 significantly ameliorated 6-month CS-induced increase in alveolar mean linear intercept (Lm) (Figure 1, C and D). Lung compliance was further augmented in $\operatorname{Sirt}^{+/-}$mice, but it was attenuated in Sirt1 Tg mice, compared with WT mice exposed to CS for
6 months (Figure 1, E and F). Sirt1 deficiency decreased total lung resistance $\left(R_{L}\right)$, although no significant change in $R_{L}$ in WT or Sirt1 $\mathrm{Tg}$ mice was observed after 6 months of CS exposure (Supplemental Figure 3, A and B). There was no difference in the central airway resistance (Rn) among Sirt1 ${ }^{+/-}$, Sirt1 Tg, and littermate WT mice (Supplemental Figure 3, C and D). Reduced exercise capacity (i.e., 6-minute walk test) is a characteristic feature of COPD/emphysema (28). Exercise tolerance was further decreased in Sirt $1^{+/-}$mice, 

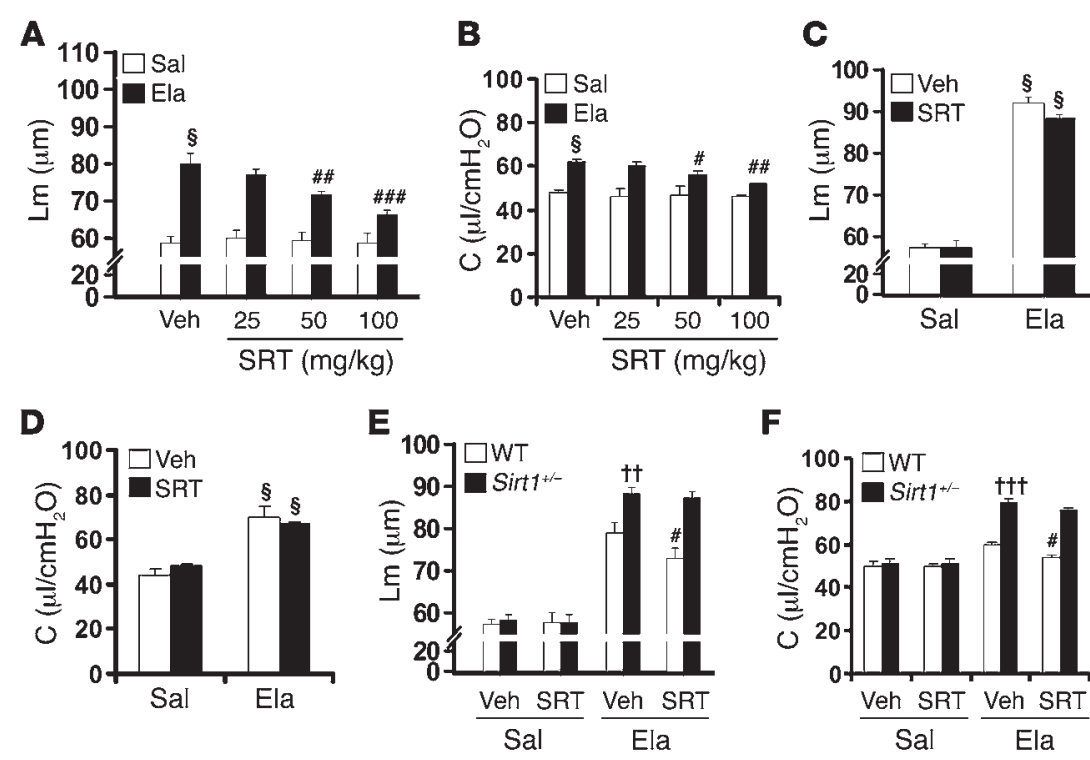

F

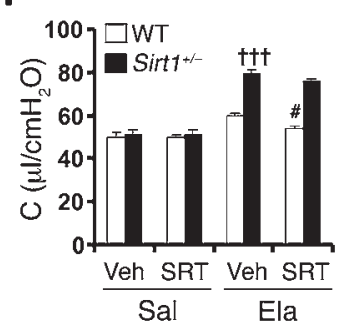

\section{Figure 2}

SRT1720 exhibits protective and therapeutic effects on elastase-induced airspace enlargement and increase in lung compliance. (A and B) Administration of SRT1720 (SRT; 50-100 mg/kg) by oral gavage during emphysema development significantly prevented elastase-induced increase in $\mathrm{Lm}$ of airspace (A) and lung compliance (B) in 129/SvJ WT mice. (C and D) Administration of SRT1720 $(100 \mathrm{mg} / \mathrm{kg}$ ) during emphysema development did not alter the airspace enlargement (C) or increased lung compliance (D) in Sirt1+/- mice. (E and F) Oral administration of SRT1720 $(100 \mathrm{mg} / \mathrm{kg})$ after the development of emphysema attenuated airspace enlargement (E) and increased lung compliance (F) in WT, but not Sirt1 ${ }^{+/}$, mice. Veh, vehicle. $n=3-4$ per group. $\$ P<0.001$ versus saline; ${ }^{\sharp} P<0.05$, $\# P<0.01$, \#\#\# $P<0.001$ versus vehicle; $t+P<0.01$, ${ }_{\mathrm{tt}} P<0.001$ versus WT. whereas Sirt1 Tg mice showed no reduction of treadmill running time or distance in response to CS exposure for 6 months (Supplemental Figure 3, E-H). Similarly, airspace enlargement, lung function decline, and decreased arterial oxygen saturation were aggravated in $\mathrm{Sirt1}^{+/-}$mice compared with WT littermates administered elastase (Figure 1, G-I, and Supplemental Figure 3, I and J). However, no difference of $\mathrm{Rn}$ was observed between Sirt $1^{+/-}$mice and WT littermates exposed to elastase (Supplemental Figure 3K).

Administration of a selective pharmacological SIRT1 activator, SRT1720 (50-100 mg/kg, orally), during emphysema development attenuated elastase-induced airspace enlargement and lung function impairment (i.e., lung compliance and $\mathrm{R}_{\mathrm{L}}$ ) as well as reduced arterial oxygen saturation in WT mice (Figure 2, A and B, and Supplemental Figure 4, A and B). However, this protective effect of SRT1720 (at $100 \mathrm{mg} / \mathrm{kg}$ ) was not seen in Sirt $1^{+/-}$mice exposed to elastase (Figure 2, C and D, and Supplemental Figure 4, C and D). SRT1720 treatment increased SIRT1 activity in lungs of WT, but not Sirt1 ${ }^{+/}$, mice (Supplemental Figure 4E). Furthermore, treatment with SRT1720 (100 mg/kg, orally) for 2 weeks after the establishment of elastase-induced emphysema significantly improved airspace enlargement and lung function decline as well as decreased arterial oxygen saturation in WT, but not Sirt1 ${ }^{+-}$, mice (Figure 2, E and F, and Supplemental Figure 4, $F$ and $G$ ). Together, these results showed the protective effect of SIRT1 and its pharmacological activator, SRT1720, against pulmonary emphysema in mice.

Sirt1 deficiency in airway epithelium, but not in myeloid cells, aggravates emphysema. CS exposure for 6 months significantly reduced the level of SIRT1 in BAL cells and lung epithelial cells in 129/SvJ mice (Supplemental Figure 5, A and B). To study the cell-specific role of SIRT1 in progression of emphysema, we generated airway epithelium- and myeloid cell-specific Sirt1 KO mice (referred to herein as Epi-Sirt1 $1^{-/-}$and Mac-Sirt1 ${ }^{-/-}$, respectively) by crossing Sirt $1^{f l}$ mice (C57BL/6J × 129/SvJ background) with mice expressing Cre recombinase from the CC10 (in Clara cells; C57BL/6J background) and lysozyme M (in myeloid cells; C57BL/6J × 129/SvJ background) promoters (29-31). SIRT1 expression and level were abolished in BAL cells (mainly alveolar macrophages) of Mac-Sirt1-/- mice com- pared with WT controls (Supplemental Figure 5, C and D). There was no SIRT1 expression in airway epithelium or isolated Clara cells from Epi-Sirt1 ${ }^{-1}$ mice (Supplemental Figure 5, E-G). Elastaseinduced increases in airspace enlargement and lung compliance were further augmented in Epi-Sirt1 ${ }^{-/-}$mice compared with WT littermates (Figure 3, A-C). $\mathrm{R}_{\mathrm{L}}$, exercise capacity, and arterial oxygen saturation were further reduced in Epi-Sirt1 $1^{-/}$mice compared with WT controls exposed to elastase (Figure 3D and Supplemental Figure 6, A and B). No significant difference of Rn was observed between Epi-Sirt1 ${ }^{-/-}$mice and WT littermates exposed to elastase (Supplemental Figure 6C). Interestingly, in Mac-Sirt1 $1^{-/}$animals, elastase injection showed no influence on airspace enlargement, lung compliance, $\mathrm{R}_{\mathrm{L}}$, exercise tolerance, or arterial oxygen saturation (Figure 3, E-H, and Supplemental Figure 6, D-F). These results suggest that Sirt1 deficiency in airway epithelium, but not in myeloid cells, aggravates emphysema in mice.

FOXO3 is required for the protection of SIRT1 against emphysema. SIRT1 interacts with FOXO3, thereby tipping the balance toward cell survival $(11,32)$. Hence, we studied whether the protection of SIRT1 against emphysema is dependent on FOXO3. CS exposure for 6 months significantly reduced the level of FOXO3 in lungs of WT and Sirt1-deficient mice, but this decline was attenuated by Sirt1 overexpression (Supplemental Figure 7A). Treatment with SRT1720 $(100 \mathrm{mg} / \mathrm{kg}$, orally) attenuated the reduction of FOXO3 protein induced by acute (3-day) CS exposure (Supplemental Figure 7B). Moreover, FOXO3 acetylation was increased in Sirt $1^{+/-}$mice, but lowered in Sirt1 Tg mice exposed to CS for 6 months (Supplemental Figure 7C). The interaction of SIRT1 with FOXO3 was disrupted in lungs of mice exposed to CS (Supplemental Figure 7D).

We next investigated whether Foxo3 deficiency alters the protective effect of SRT1720 on emphysematous phenotype. In contrast with the findings in WT littermates, there was no protective effect of SRT1720 (100 mg/kg, orally) on elastase-induced increase in $\mathrm{Lm}$ of airspace or lung compliance in Foxo $3^{-/-}$mice $($ FVB $\times 129$ S6 background) (Figure 4, A-C). Similarly, SRT1720 administration during the development of emphysema had no effect on $\mathrm{R}_{\mathrm{L}}$, exercise tolerance, or arterial oxygen saturation in Foxo3 $3^{-/}$mice in response to elastase administration (Figure 4, 
A
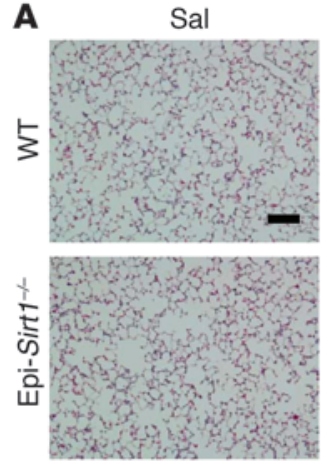

E
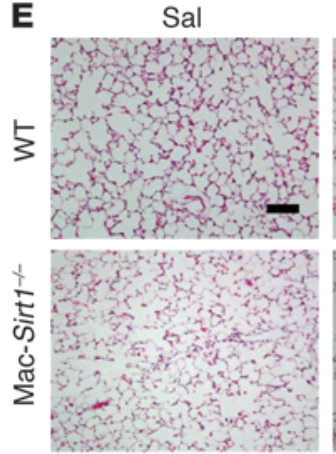

Ela

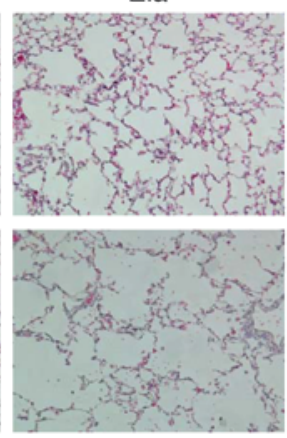

Ela

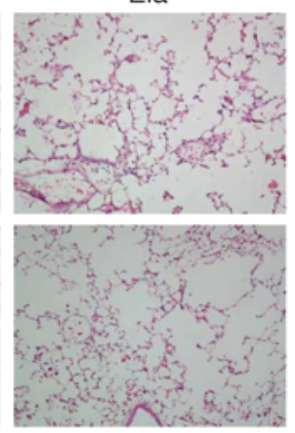

B

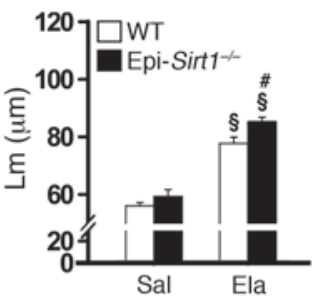

C

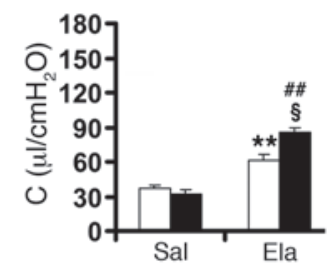

G

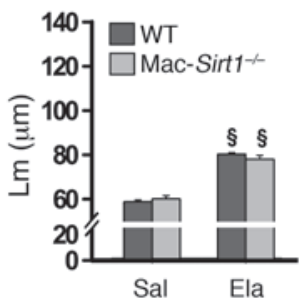

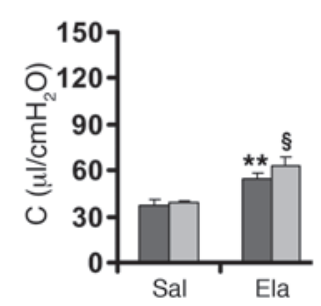

D

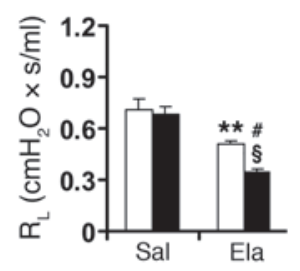

H

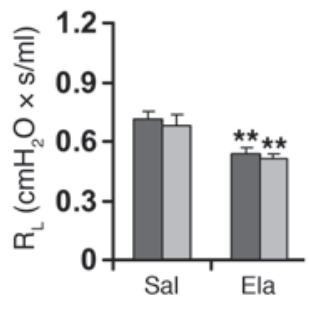

Figure 3

Elastase-induced airspace enlargement and lung function decline are further aggravated in Epi-Sirt1 ${ }^{-/-}$, but not in Mac-Sirt1 ${ }^{-/}$, mice. (A and B) Elastase-induced airspace enlargement was increased in Epi-Sirt1-/- mice compared with WT littermates. (C) Deficiency of Sirt1 in airway epithelium led to an increase in lung compliance in response to elastase exposure. (D) $R_{L}$ was further reduced in Epi-Sirt1-- mice exposed to elastase. ( $\mathbf{E}$ and $\mathbf{F})$ No significant difference in $\mathrm{Lm}$ of airspace was seen between Mac-Sirt1 ${ }^{-/-}$and WT mice after elastase intratracheal injection. (G and $\left.\mathbf{H}\right)$ The myeloid cell-specific deficiency of Sirt1 (in Mac-Sirt1-/- mice) did not affect lung compliance $(\mathbf{G})$ or $\mathrm{R}_{\mathrm{L}}(\mathbf{H})$ in response to elastase exposure.

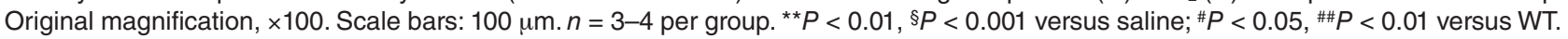

D-F). Therefore, FOXO3 was an essential mediator in the beneficial effect of SIRT1 against emphysema.

SIRT1 attenuates CS-induced cellular senescence via FOXO3. CS exposure can cause cellular senescence in lungs of patients with COPD/ emphysema $(3,19-24,33)$. We found that the level of SIRT1 was decreased, whereas senescence-associated $\beta$-gal (SA- $\beta$-gal) activity and p21 expression were increased in lungs of COPD patients compared with nonsmokers (Supplemental Figure 8, A-D). Therefore, it is possible that the protective effect of SIRT1 in emphysema is associated with its ability to regulate cellular senescence. As expected, CS exposure significantly increased the levels of prosenescent proteins (i.e., p21, p16, and p53) and SA- $\beta$-gal activity in lungs of $\operatorname{Sirt}^{+1-}$ mice versus WT littermates, whereas these levels were lowered by Sirt 1 overexpression (Figure 5 and Figure 6, A and B). Similarly, the prophylactic and therapeutic administration of SRT1720 (100 mg/kg, orally) significantly attenuated the SA$\beta$-gal activity in lungs of WT mice, but not in Sirt $1^{+/-}$mice, exposed to elastase (Figure 6, C and D). Interestingly, the SA- $\beta$-gal activity was increased in Epi-Sirt1 $1^{-/}$, but not in Mac-Sirt1 1/-, mice after elastase administration compared with corresponding WT littermates (Figure 6, E and F). Together, these data suggest that SIRT1 protects against SIPS in mouse lung.

To further study the contribution of FOXO3 to SIRT1's protection against cellular senescence, we determined the premature senescence in $\mathrm{Foxo}^{-/-}$mice exposed to CS for 4 months. Foxo3 $3^{-/-}$mice exhibited heightened levels of p21, p16, p27, and SA- $\beta$-gal activ- ity in lungs in response to CS exposure (Figure 7). Strikingly, the augmented levels of p21 and SA- $\beta$-gal activity in lungs of Foxo3-/mice were not attenuated by SRT1720 after elastase administration (Figure 8, A and B). Consistent with this, SRT1720 treatment failed to alter the lung levels of p16, p27, or p53 in Foxo $3^{-/-}$mice exposed to elastase (Figure $8 \mathrm{C}$ ). These findings suggest that FOXO3 is required for SIRT1-mediated protection against SIPS.

p21 deficiency attenuates CS-induced emphysema associated with reduction of cellular senescence. To determine the role of cellular senescence in emphysema, we exposed the prosenescent gene knockout (i.e., p21 $1^{-1-}, \mathrm{C} 57 \mathrm{BL} / 6 \mathrm{~J}$ background) mice to CS for 6 months (34). The airspace enlargement and increased lung compliance were significantly ameliorated in $p 21^{-/-}$mice compared with WT mice exposed to CS (Figure 9, A-C). No change in $\mathrm{R}_{\mathrm{L}}$ was observed in either WT or $p 21^{-1-}$ mice after 6 months of CS exposure (Figure 9D). Furthermore, $p 21$ deficiency reduced SA- $\beta$-gal activity in mouse lung in response to 6 months of CS exposure (Figure 9E). We next investigated whether $\mathrm{p} 21$ deficiency protects against cellular senescence induced by the SIRT1 inhibitor sirtinol in response to CS exposure. Treatment with sirtinol $(2 \mathrm{mg} / \mathrm{kg}$ i.p.) further increased SA- $\beta$-gal activity in lungs of WT mice exposed to CS for 3 days (Figure 9F). However, there was no significant change in SA- $\beta$-gal activity in lungs of $p 21^{-1-}$ mice in response to CS exposure, or along with sirtinol treatment (Figure 9F). All these results indicate that SIRT1 regulates $\mathrm{p} 21$-mediated lung cell senescence, which is a key contributing factor in the development of emphysema. 
A

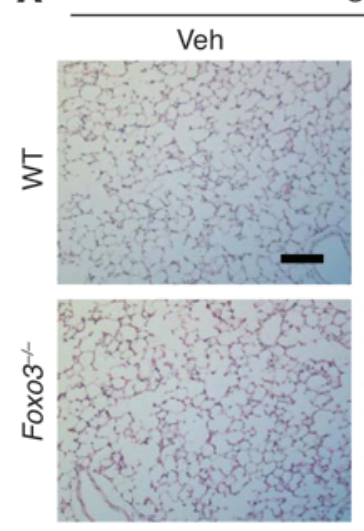

c

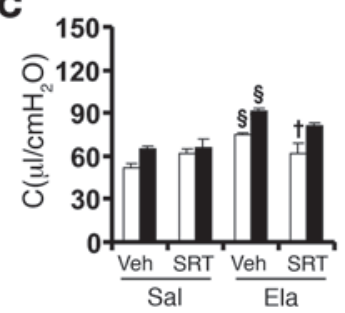

Sal

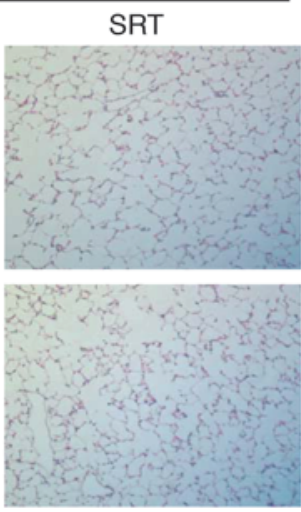

D

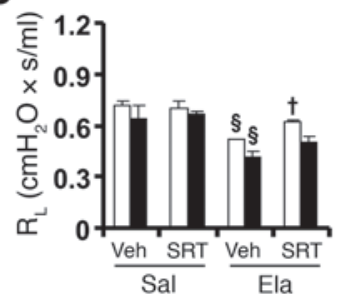

Ela

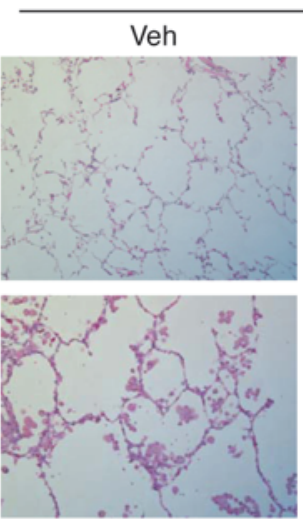

E

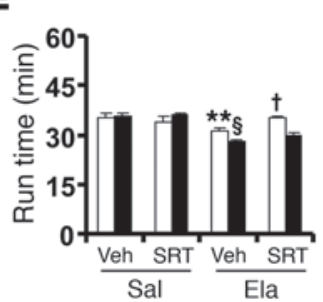

B

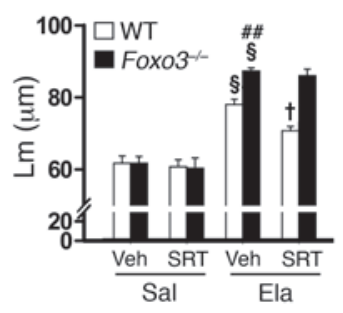

Figure 4

Foxo3 deficiency diminishes the protection of SRT1720 against elastase-induced emphysema. (A and B) SRT1720-mediated protection against elastase-induced airspace enlargement was diminished in Foxo3 ${ }^{-/-}$mice. (C and D) No effect of SRT1720 on lung compliance (C) or $\mathrm{R}_{\mathrm{L}}(\mathbf{D})$ was observed in Foxo3 ${ }^{-1-}$ mice exposed to elastase. (E and $\left.\mathbf{F}\right)$ Treadmill running time $(\mathbf{E})$ and arterial oxygen saturation $(\mathbf{F})$ were decreased in Foxo3 $3^{-/}$mice in response to elastase intratracheal injection, which was not altered by SRT1720. H\&E-stained images are representative of experiments from 3 separate mice. Original magnification, $\times 100$. Scale bar: $100 \mu \mathrm{m} . n=3-4$ per group. ${ }^{* \star} P<0.01, \S P<0.001$ versus saline; $\#$ \# $P<0.01$ versus $\mathrm{WT} ;{ }^{\dagger} P<0.05,{ }^{\dagger}+P<0.01$ versus vehicle.

Protection of SIRT1 against emphysema is not attributed to its effect on inflammation. SIRT1 deacetylates RelA/p65, which is activated in lungs of patients with COPD $(18,35,36)$. SIRT1 attenuated RelA/ p65 acetylation in mouse lung with emphysema triggered by CS (Supplemental Figure 9A). Consequently, SIRT1 alleviated inflammatory cell influx into BAL fluid in response to both 3 days and 6 months of CS exposures (Supplemental Figure 9, B-E). Neutrophil influx into BAL fluid was further increased in Epi-Sirt1 ${ }^{-1}$ mice, whereas there was no significant difference in neutrophil number in BAL fluid of Mac-Sirt1 1/- mice compared with their WT littermates exposed to CS for 3 days (Supplemental Figure 9, F and $\mathrm{G})$. Elastase-induced neutrophil influx was also further increased in Sirt1 $1^{+/}$mice (Supplemental Figure 9H). Additionally, administration of SRT1720 $(100 \mathrm{mg} / \mathrm{kg}$, orally $)$ significantly decreased neutrophil influx into BAL fluid of WT mice in response to CS (3 days) and elastase exposure (Supplemental Figure 10, A and B), which was associated with the increased SIRT1 activity in mouse lung (Supplemental Figure 4E and Supplemental Figure 10C). To determine the role of NF- $\mathrm{KB}$ in lung inflammatory response, we then treated Sirt1 ${ }^{+-}$and WT mice with a selective IKK2/NF-кB inhibitor (PHA-408; $50 \mathrm{mg} / \mathrm{kg}$, orally) in response to CS (3 days) exposure and elastase injection. PHA-408 administration significantly reduced neutrophil influx into BAL fluid in both WT and Sirt $1^{+/-}$mice (Supplemental Figure 10, D and E). Interestingly, the efficacy of PHA-408 in attenuating neutrophil influx was higher in Sirt1 $1^{+-}$mice (CS, 67.3\%; elastase, $56.8 \%$ ) than in WT littermates (CS, 49.9\%; elastase, $39.8 \% ; P<0.05)$. These results suggest that SIRT1

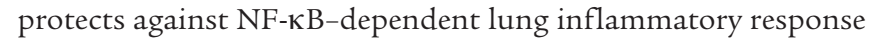
to both CS exposure and elastase intratracheal injection.

Finally, we determined whether PHA-408 also attenuates elastaseinduced emphysema. Surprisingly, PHA-408 administration was unable to alter elastase-induced airspace enlargement or increased lung compliance in either WT or Sirt1 ${ }^{+/-}$mice (Figure 10, A-C). Moreover, elastase-induced decrease in $\mathrm{R}_{\mathrm{L}}$, arterial oxygen saturation, and treadmill running time was not significantly affected by PHA-408 treatment (Figure 10, D-F). SA- $\beta$-gal activity in elastaseexposed mouse lung was also not altered by PHA-408 (Figure 10G). Therefore, NF- $\kappa \mathrm{B}$-dependent inflammation was not involved in lung tissue damage or emphysematous destruction in mice.

\section{Discussion}

We and others have previously shown that the level of SIRT1 is substantially decreased in lungs of patients with COPD/emphysema as well as in lungs of rodents exposed to CS $(17,18,37,38)$. However, the role of endogenous SIRT1 in the development of emphysema remains elusive. We therefore studied the role of SIRT1 in the pathogenesis of emphysema in mice using various genetic and pharmacological approaches. Our findings indicate that SIRT1 protected against CS- and elastase-induced airspace enlargement, decline in lung function, impaired exercise endurance, and decreased arterial oxygen saturation, which are the characteristic features of COPD/emphysema. Furthermore, Sirt1 deletion in airway epithelium, but not in myeloid cells, aggravated airspace enlargement and lung function decline induced 


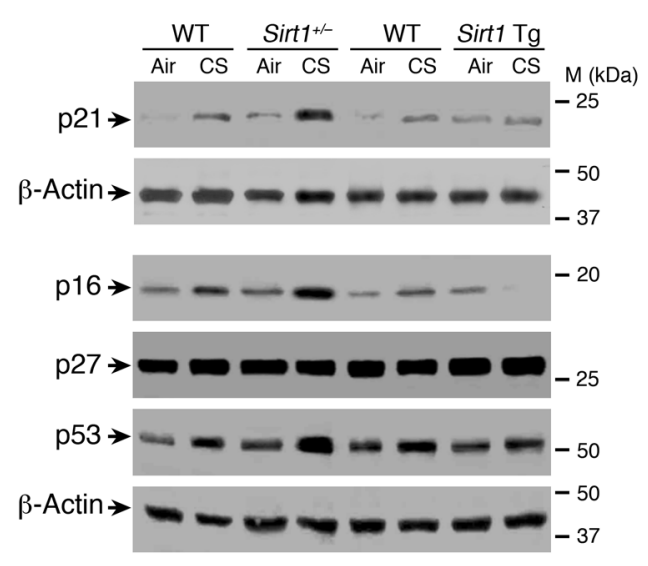

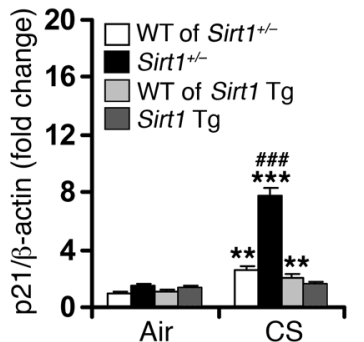
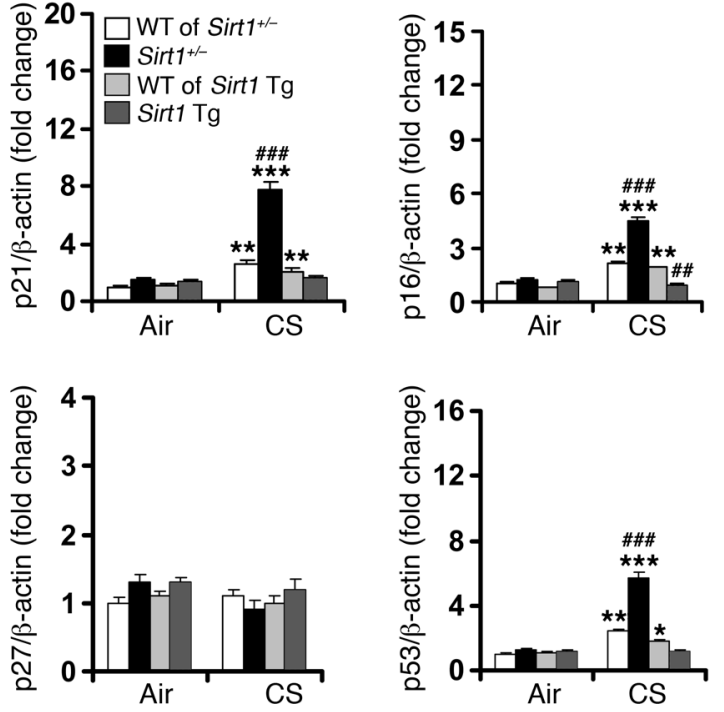

Figure 5

SIRT1 protects against CS-induced increase in p21, p16, and p53. Lung levels of p21, p16, and p53 were increased in Sirt1+/- mice versus WT littermates exposed to CS for 6 months, which was attenuated by Sirt1 overexpression. No significant change was observed in p27 level among these mice. Blots are representative of experiments from 3 separate mice. Band density is expressed as fold change relative to corresponding $\beta$-actin. $n=3-4$ per group. ${ }^{*} P<0.05,{ }^{* \star} P<0.01,{ }^{* \star *} P<0.001$ versus air; ${ }^{\# \# \#} P<0.001$ versus WT.

by elastase. Collectively, these observations suggest that SIRT1 exhibits a cell-specific protective role in emphysema. SIRT1 level and activity were reduced in an age-dependent manner in rodent lungs, as shown in this study and supported by others (39). Interestingly, the Sirt1-deficient mice developed spontaneous airspace enlargement only after 1 year of age, although a significant reduction in SIRT1 occurred at 6-8 months of age in the lungs of these mice. Additionally, Sirt1-deficient mice at 6 months of age developed emphysema after CS exposure for 4 months, whereas 6 months of CS exposure was required to develop emphysema in WT mice. This suggests that SIRT1 reduction in early life is not enough to cause lung injury, but increases the susceptibility to develop stress-induced emphysema.

In agreement with the previous studies $(40,41)$, chronic CS exposure did not alter $\mathrm{R}_{\mathrm{L}}$, which was significantly decreased in elastaseexposed mice, suggesting that the reduction of $\mathrm{R}_{\mathrm{L}}$ occurs only in the setting of more severe emphysema. This was further corroborated by the findings in Sirt1-deficient mice, which exhibited lower $\mathrm{R}_{\mathrm{L}}$ and enhanced airspace enlargement than did WT littermates in response to both chronic CS and elastase exposures. However, the Rn was not altered by either CS or elastase exposure, or loss or gain of function of SIRT1. These results suggest that peripheral airway resistance is lower in the condition of severe emphysema, which may be due to increased destruction of small airways. These findings in the mouse model of emphysema are in contrast to the increased $\mathrm{R}_{\mathrm{L}}$ seen in human COPD (42). This may be attributed to the anatomical features of mouse lung, such as the relatively large airway size and lack of submucosal glands, which might not cause the narrowing and obstruction of conducting airways (43). We noted that the Lm value was about 50-60 $\mu \mathrm{m}$ in air- and salineexposed WT control mice, which is consistent with previous findings (44-46). However, some studies have shown that the Lm of airspace is about $25-35 \mu \mathrm{m}$ in WT control mice (47-50). The discrepancy in Lm of airspace among these studies may be associated with the differences in CS doses, pattern/composition of smoke delivered by different CS generating systems, mouse strains, and techniques used for measuring Lm. Nonetheless, 6 months of CS exposure and elastase intratracheal injection increased the $\mathrm{Lm}$ of airspace by approximately $19 \%$ and $38 \%$, respectively. This was corroborated by the previous findings showing $15 \%-20 \%$ increase of Lm by chronic CS exposure, and $25 \%-45 \%$ increase by elastase administration (45, 47-49).

SIRT1 deacetylates FOXO3 via direct protein-protein interaction, thereby tipping the balance to cellular survival in response to oxidative/carbonyl stress $(11,32,51)$. Our previous study showed an increase in both FOXO3 degradation and acetylation in lungs of COPD patients and mouse lung exposed to CS (51). This was due to the reduction of SIRT1 level and its interaction with FOXO3 in response to CS exposure. However, it remains to be seen which residues of FOXO3 are acetylated by $\mathrm{CS}$ and regulated by SIRT1. Furthermore, the study is required to determine whether the increased acetylation marks FOXO3 for its degradation, as well as alters its transactivation on target genes (e.g., prosenescent versus antioxidant genes). Nevertheless, we have shown that Foxo3 deficiency increases the susceptibility of mice to develop emphysema (51). Interestingly, the protective effect of a selective pharmacological SIRT1 activator, SRT1720, against emphysema was diminished in Foxo3 KO mice. These findings suggest that the beneficial effect of SIRT1 on emphysema requires FOXO3.

Accumulating evidence supports the notion that COPD is a disease of accelerated and premature aging, as enhanced oxidative stress and cellular senescence occur in lungs and systemic circulation of patients with this disease $(3,19,22,23,33,47,52)$. Therefore, we proposed that an age-dependent cellular senescence would be a target for the protection of SIRT1 against emphysema in mice. CS exposure significantly induced premature senescence in mouse lung, which was attenuated by SIRT1 overexpression and by its activator, SRT1720. This is corroborated by the finding that 
A
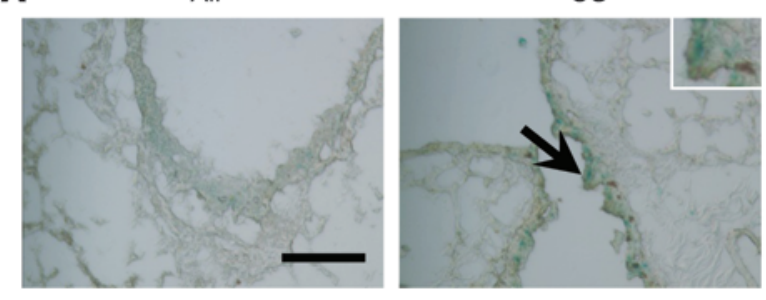

B

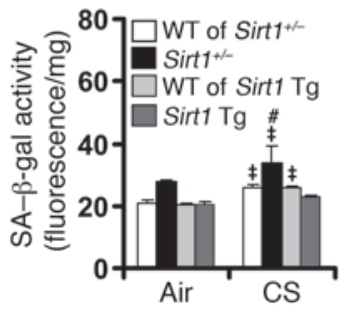

C

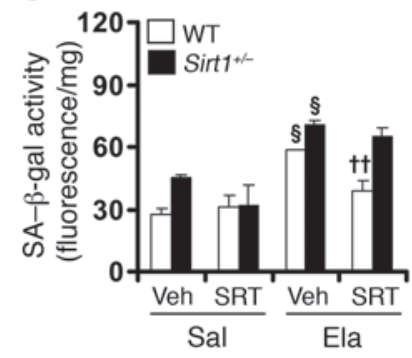

D

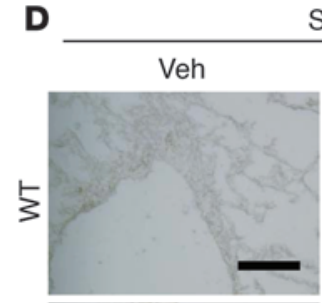

Sal
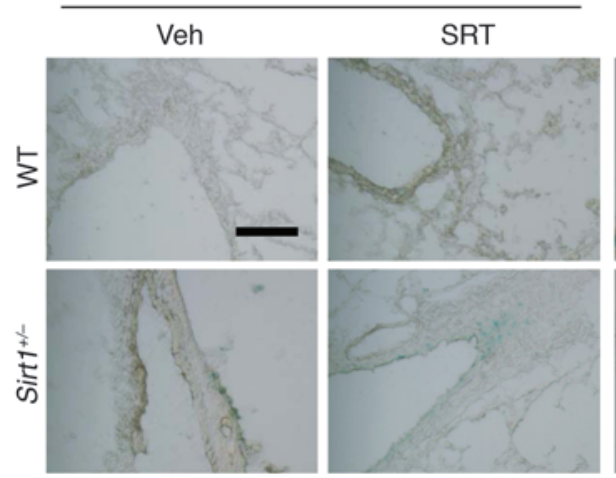
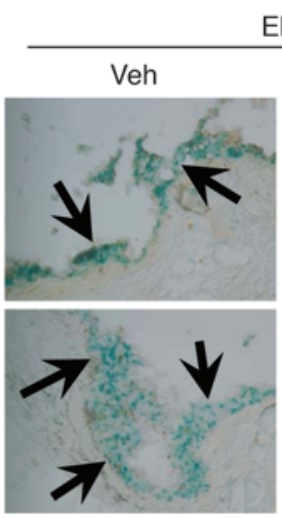

Ela

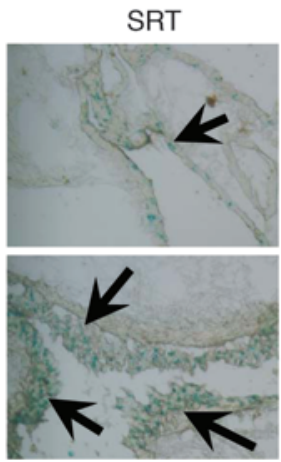

E

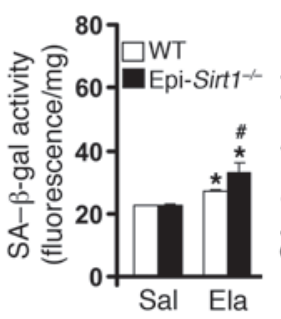

$\mathbf{F}$

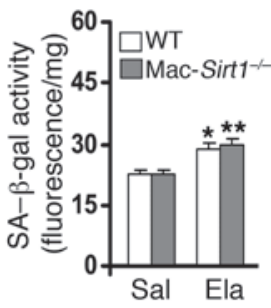

\section{Figure 6}

SIRT1 protects against CS- or elastase-induced increase in lung SA- $\beta$-gal activity. (A) CS exposure for 3 days increased lung SA- $\beta$-gal activity (arrows). (B) Whereas SA- $\beta$-gal activity was increased by Sirt1 deficiency when exposed to CS for 6 months, this was not observed in lungs of Sirt1 Tg mice. (C) SRT1720 administration prior to emphysema development attenuated SA- $\beta$-gal activity in lungs of WT, but not Sirt1+/-, mice in response to elastase exposure. (D) SRT1720 administration after emphysema development for 2 weeks ameliorated elastase-induced increase in lung SA- $\beta$-gal activity (arrows). (E and F). SA- $\beta$-gal activity was increased in lungs of Epi-Sirt1---, but not Mac-Sirt1-/-, mice compared with their WT littermates after elastase injection. Original magnification, $\times 200 ; \times 400$ (inset). Scale bars: $100 \mu \mathrm{m}$. SA- $\beta$-gal activity is expressed as 4-MU fluorescence normalized to protein content (see Methods). $n=3-4$ per group. ${ }^{\ddagger} P<0.05$ versus air; ${ }^{*} P<0.05$, ${ }^{\star *} P<0.01$, , $P<0.001$ versus saline; ${ }^{\#} P<0.05$ versus WT; ${ }^{\dagger} P<0.01$ versus vehicle.

SIRT1 protects against telomere shortening and erosion (a biological maker of replicative senescence) (53). However, the role of SIRT1 in CS-induced replicative senescence is unclear, although telomere length is a determinant of emphysema susceptibility (54). Furthermore, the lung levels of p16, p21, and p27, as well as SA$\beta$-gal activity, were further increased in Foxo3-deficient mice with emphysema, which was supported by a prior study showing the protection of FOXO3 against cellular senescence (14). Strikingly, Foxo3 deficiency diminished the effect of SRT1720 in attenuating the levels of p21 and p16 as well as SA- $\beta$-gal activity in emphysematous lungs, indicative of the requirement of FOXO3 for SIRT1's protection against SIPS. Importantly, deletion of p21 significantly ameliorated CS-induced airspace enlargement and lung function decline. Both CS and sirtinol induced an increase in SA- $\beta$-gal activity in mouse lung, which was significantly attenuated by $p 21$ deficiency. Hence, SIRT1 activation downregulated SIPS through FOXO3/p21 pathway, thereby protecting against emphysema. In addition to FOXO3, recent studies have demonstrated the involvement of other developmental and senescence-related genes, such as Wnt/ $\beta$-catenin, Notch, Klotho, senescence marker protein-30, and Werner syndrome protein, in the development of emphysema (55-60). However, it remains to be seen whether SIRT1 targets these genes in response to CS exposure.

SIRT1 has been shown to upregulate FOXO3-dependent antioxidant genes (i.e., catalase and MnSOD) and to protect against oxidative stress-induced cellular apoptosis (61-64). Moreover, FOXO3 forms a complex network along with p53 in regulating cellular responses to oxidative stress, such as senescence, proliferation, and apoptosis $(11,65,66)$. This suggests the involvement of SIRT1/FOXO3/p53-dependent signaling in regulating cellular senescence. Both oxidative stress and apoptosis play an important role in the development of COPD/emphysema (44, $47,50,67)$. Hence, it is likely that SIRT1 augmentation alleviates emphysema via downregulating oxidative stress-mediated cellular senescence and apoptosis.

Chronic CS exposure reduced the level of SIRT1 in BAL cells (mainly composed of macrophages) and lung epithelial cells in mice. This is consistent with our previous studies showing SIRT1 reduction in monocytes/macrophages, lung epithelial cells, endothelial cells, and fibroblasts treated with CS extract in vitro $(18,38,68,69)$. Interestingly, SA- $\beta$-gal activity in lungs was increased in mice with SIRT1 deficiency in Clara cells, but not in myeloid cells, compared with corresponding WT littermates in response to elastase administration. Furthermore, the SA- $\beta$-galpositive cells were mainly localized in the airway epithelium of emphysematous mice and COPD patients. These results indicate the importance of SIRT1 reduction associated with senescence in Clara cells (the progenitor cells of the peripheral airway epithelium) in the development of emphysema. This is in agreement with increased number of senescent Clara cells in lungs of patients with 
A

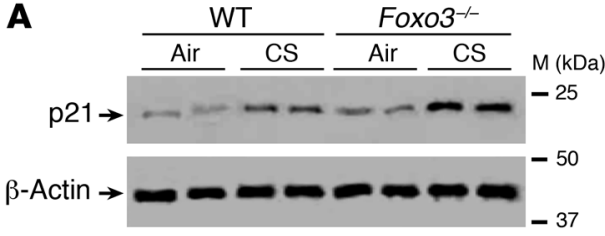

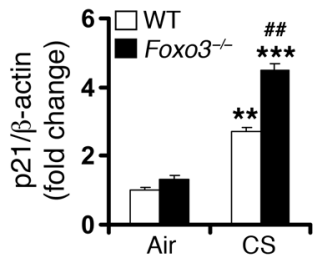

B

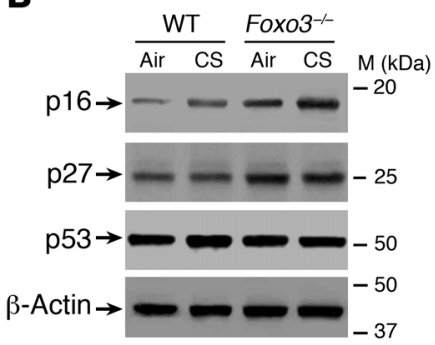

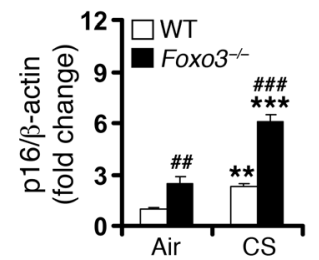

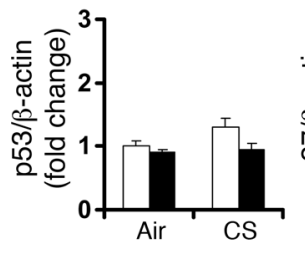

C

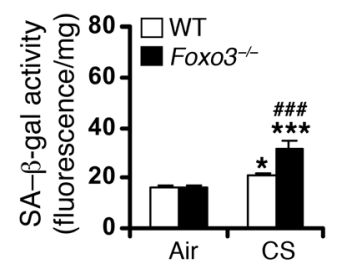

Figure 7

CS-induced lung cellular senescence is increased in Foxo3--- mice. (A) Lung level of p21 was increased in Foxo3 $3^{-/-}$mice versus WT littermates exposed to CS for 4 months. (B) Foxo3 deficiency increased the levels of p16 and p27, but not p53, in lungs of mice exposed to CS for 4 months. (C) SA- $\beta$-gal activity was increased in lungs of Foxo3 $3^{-1}$ mice compared with WT littermates after 4 months of CS exposure. Blots are representative of experiments from 3 separate mice. Band density is expressed as fold change relative to corresponding $\beta$-actin. SA- $\beta$-gal activity is expressed as 4-MU fluorescence normalized to protein content (see Methods). $n=3$ per group. ${ }^{*} P<0.05,{ }^{* *} P<0.01,{ }^{* * *} P<0.001$ versus air; $\# P<0.05, \# P<0.01, \# \# P<0.001$ versus WT.

COPD compared with nonsmokers (52). Nevertheless, the possibility that SIRT1 regulates senescence in fibroblasts and endothelial cells cannot be excluded. In addition, the SIRT1/FOXO3 axis may be involved in the regulation of lymphocyte senescence, thereby preventing the recognition of self-antigens particularly in mice with emphysema, since SIRT1 attenuated autoimmunity reaction by inhibiting $\mathrm{T}$ cell activation $(9,19,21,70)$.

Inflammation and cellular senescence are intertwined in the process of accelerated or premature lung aging (inflammaging) (71). The percentage of proinflammatory senescent type II cells expressing both p16 and phosphorylated NF-KB (i.e., senescence-associated secretory phenotype [SASP]) has been shown to be augmented in lungs of COPD patients compared with smokers and nonsmokers (33). Senescent cells are prone to generate proinflammatory mediators, which may reinforce the senescence growth arrest or mobilize innate immune cells to clear senescent/senesced cells (72-74). Consistent with this, both SIRT1 and genetic disruption of the prosenescent gene $p 21$ attenuated CS-induced lung inflammation, which was associated with reduced NF- $\mathrm{KB}$ activation (34). Interestingly, the inhibition of lung inflammation using the selective NF-KB/IKK2 inhibitor PHA-408 did not affect cellular senescence or emphysematous destruction. This observation suggests that NF-кB-dependent lung inflammation does not contribute to lung dysfunction or that it is just one of the consequences of cellular senescence.

It has previously been shown that SIRT1 negatively regulates MMP-9 by lowering NF- $\kappa$ B activation (17). We found that the level and activity of MMP-9 were further increased in lungs of Sirt1deficient mice, which were attenuated by Sirt1 overexpression in response to CS exposure (H. Yao and I. Rahman, unpublished observations). Furthermore, mice overexpressing MMP-9 develop lung emphysematous phenotype, whereas MMP-9-deficient mice are protected from IL-13-induced airspace enlargement $(75,76)$. These findings suggest the possible involvement of MMPs in SIRT1-mediated regulation of emphysema via an unknown mechanism.
In conclusion, SIRT1 protected against emphysema through a FOXO3-dependent antisenescent mechanism. Furthermore, the inhibition of NF-кB-dependent inflammation with PHA-408 did not exhibit any protective effect in elastase-induced airspace enlargement or decline in lung function. Therefore, the antisenescent, but not antiinflammatory, property contributes to the protection of SIRT1 against emphysema (Figure 11). These findings highlight the mechanism of SIPS in the pathogenesis of COPD/emphysema. They also provide the rationale for a key and specific therapeutic target via pharmacological activation of SIRT1 in ameliorating/halting the progression of this diverse and complex debilitating disease $(71,77)$. Hence, the activation of SIRT1 may prove a therapeutic intervention to prevent premature lung senescence/aging in COPD.

\section{Methods}

Mice. Generation of Sirt1 ${ }^{+/-}$and Sirt1 Tg mice was described previously $(26,27)$. Sirt 1 heterozygous KO mice were used, since Sirt1 homozygous KO mice have low perinatal survival rate (26). Epi-Sirt1 ${ }^{-/-}$mice (Clara cell-specific Sirt1 deletion) were generated by crossing Sirt $1^{f l}$ mice (B6;129Sirt $1^{\text {tm } 1 Y g^{u}} / \mathrm{J}$; The Jackson Laboratory) with mice expressing the Cre recombinase transgene under control of the CC10 promoter (C57BL/6; obtained from T.J. Mariani, University of Rochester, Rochester, New York, USA). Mac-Sirt1 $1^{-/}$mice (myeloid cell-specific Sirt1 deletion) were generated by crossing $\operatorname{Sirt}_{11^{l}}$ mice with mice expressing the Cre recombinase transgene

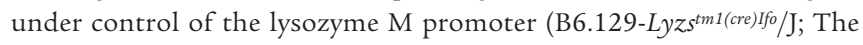

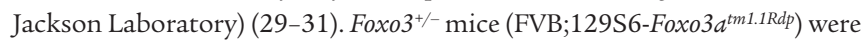
obtained from the Mutant Mouse Regional Resource Centers, University of California Davis (stock no. 016132-UCD) (78). Foxo3 $3^{-/-}$mice and their WT littermates were generated and used in the experiments. $p 21^{-/-}$mice were obtained from M. O'Reilly (University of Rochester, Rochester, New York, USA), who backcrossed them 10 generations to C57BL/6J after receiving from P. Leder (Harvard Medical School, Boston, Massachusetts, USA) (34). All mice were housed in the vivarium facility of the University of Rochester with a 12-hour light/12-hour dark cycle (light on at 6:00 am). 
A
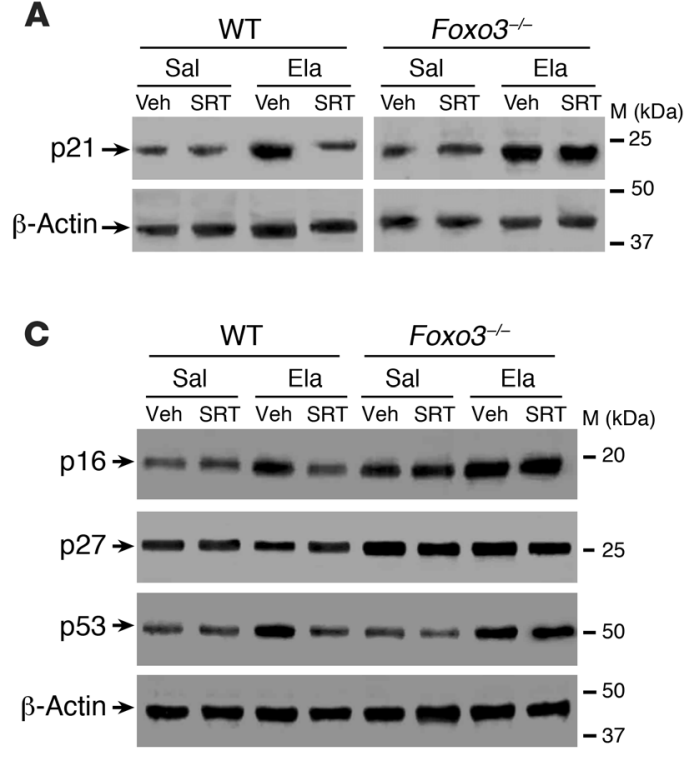

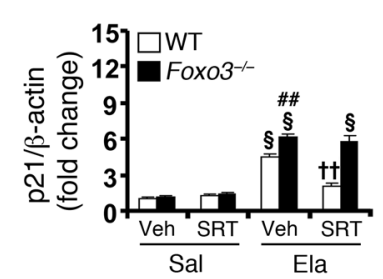

B

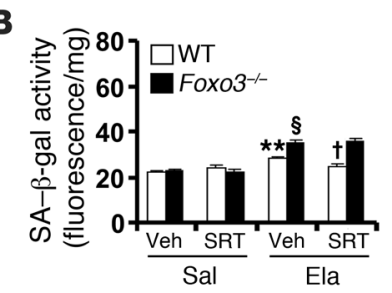

\section{Figure 8}

SRT1720 protection against lung senescence is diminished in Foxo3 ${ }^{-/-}$mice exposed to elastase. (A) SRT1720 administration before emphysema development reduced elastase-induced increase in the level of p21 in WT mouse lung, which was diminished in Foxo3-/- mice. (B) Elastase-induced increase in SA- $\beta$-gal activity was attenuated by SRT1720 in WT mice, which was diminished in Foxo3 $3^{-/-}$mice. (C) Attenuation in levels of p16 and p53, but not p27, in lungs by SRT1720 was diminished in Foxo3 ${ }^{-/-}$mice exposed to elastase. Blots are representative of experiments from 3 separate mice. Band density is expressed as fold change relative to corresponding $\beta$-actin. SA- $\beta$-gal activity is expressed as 4-MU fluorescence normalized to protein content (see Methods). $n=3$ per group. ${ }^{\star \star} P<0.01, \$ P<0.001$ versus saline; ${ }^{\#} P<0.05$, \#\# $P<0.01$ versus $\mathrm{WT} ;{ }^{\dagger} P<0.05,{ }^{\dagger \dagger} P<0.01$ versus vehicle.

CS exposure. 8-week-old mice were used for CS exposure as described previously $(34,40,79)$. For studies involving 3 days of CS exposure, researchgrade cigarettes (3R4F; University of Kentucky) were used to generate smoke, and mice were exposed to CS according to the Federal Trade Commission protocol (1 puff/min of $2 \mathrm{~s}$ duration and $35 \mathrm{ml}$ volume) with a Baumgartner-Jaeger CSM2072i automatic CS-generating machine $(\mathrm{CH}$ Technologies). Mainstream CS was diluted with filtered air and directed into the exposure chamber. The total particulate matter (TPM) per cubic meter of air in the exposure chamber was monitored in real time with a MicroDust Pro-aerosol monitor (Casella CEL) and verified daily by gravimetric sampling (79). CS concentration was set at a value of approximately $300 \mathrm{mg} / \mathrm{m}^{3} \mathrm{TPM}$ by adjusting the flow rate of the diluted medical air, and the level of carbon monoxide in the chamber was $350 \mathrm{ppm}(79,80)$. Mice received 2 1-hour exposures (1 hour apart) daily for 3 consecutive days, then sacrificed 24 hours after the last exposure. Control mice were exposed to filtered air in an identical chamber according to the same protocol described for CS exposure. For 2-, 4-, and 6-month CS exposures, $3 \mathrm{R} 4 \mathrm{~F}$ cigarettes were used to generate a mixture of sidestream smoke (89\%) and mainstream smoke (11\%) by a Teague smoking machine (Model TE-10; Teague Enterprises) at a concentration of approximately $100 \mathrm{mg} / \mathrm{m}^{3}$ TPM, so as to avoid possible toxicity to mice at a high concentration of long-term CS exposure (40). Each smoldering cigarette was puffed for 2 seconds, once per minute for a total of 8 puffs, at a flow rate of $1.05 \mathrm{l} / \mathrm{min}$, to provide a standard puff of $35 \mathrm{~cm}^{3}$. Mice received 5 -hour exposures per day, 5 days per week, for 2, 4, or 6 months, then sacrificed 24 hours after the last CS exposure.

Intratracheal administration of porcine pancreatic elastase. Mice were suspended at $50^{\circ}-60^{\circ}$ by securing the upper incisor teeth to the board after anesthesia with ketamine $(100 \mathrm{mg} / \mathrm{kg}$ i.p.). The tongue was pulled forward, and the oropharynx was maximally exposed with the help of small animal laryngoscope (Penn-Century Inc.). The MicroSpray tip (PennCentury Inc.) was endotracheally inserted, and $100 \mu \mathrm{l}$ of saline alone or saline containing $1 \mathrm{U}$ of porcine pancreatic elastase (Sigma-Aldrich) was sprayed into the trachea (40).

Administration of SRT1720, sirtinol, and PHA-408. Sirtinol (2 mg/kg; Calbiochem) was administered by peritoneal injection, whereas SRT1720 $(100 \mathrm{mg} / \mathrm{kg}$, >95\% pure by C-13 NMR and LCMS; synthesized from Life Chemicals) was administered through oral gavage 1 hour prior to CS exposure daily for 3 days (81-83). In a separate experiment, SRT1720 (25, 50 , and $100 \mathrm{mg} / \mathrm{kg}$ ) or PHA-408 (8-[5-chloro-2-\{4-methylpiperazin-1-

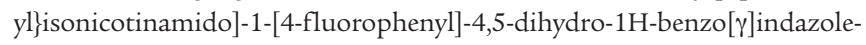
3 -carboxamide; $50 \mathrm{mg} / \mathrm{kg}$; Pfizer) was dissolved in $0.5 \%$ carboxymethylcellulose containing $0.025 \%$ Tween 20 and injected via oral gavage into the conscious mice 24 hours prior to elastase administration, which was repeated daily (5 days per week) until 21 days after elastase administration $(81,84)$. To study the therapeutic effect on emphysema, SRT1720 (100 $\mathrm{mg} / \mathrm{kg}$ ) was orally administered daily for 2 weeks after the development of elastase-induced emphysema.

Endurance exercise performance. Exercise endurance in mice was measured using a motorized rodent treadmill with an electric grid at the rear of the treadmill (Columbus Instruments), as described previously (40,85). Run duration (in minutes) and run distance (in meters, calculated based on run time and treadmill speed) were used as the parameters to reflect exercise capacity. Mice were placed on the treadmill and allowed to adapt to the surroundings for 3-5 minutes before starting the exercise. The treadmill was started at a speed of $8.5 \mathrm{~m} / \mathrm{min}$ with a $0^{\circ}$ incline. After 9 minutes, the speed and incline were raised to $10 \mathrm{~m} / \mathrm{min}$ and $5^{\circ}$, respectively. Speed was increased $2.5 \mathrm{~m} / \mathrm{min}$ every 3 minutes to a maximum of $40 \mathrm{~m} / \mathrm{min}$, and the incline was increased $5^{\circ}$ every 9 minutes to a maximum of $15^{\circ}$. Exercise continued until mouse exhaustion, defined as an inability to maintain 
A
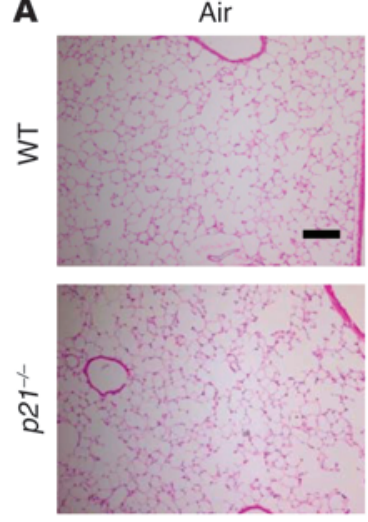

D

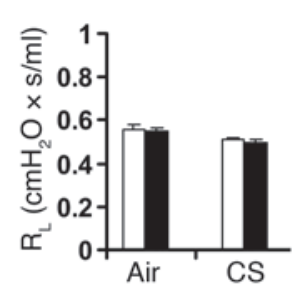

CS
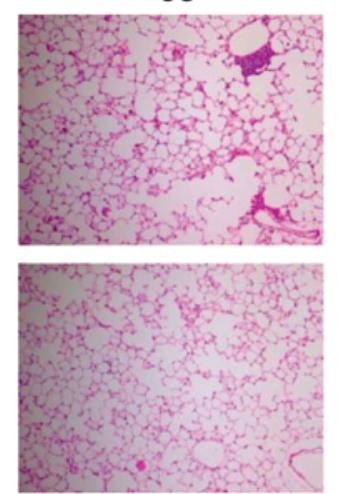

E

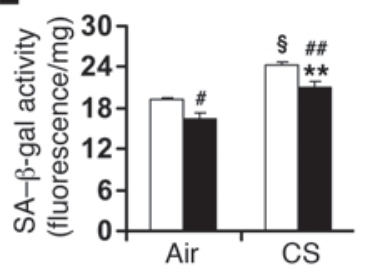

B

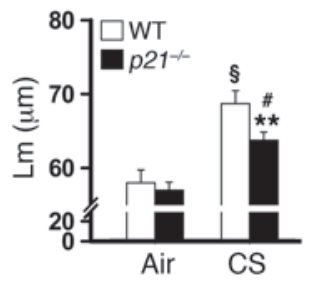

C

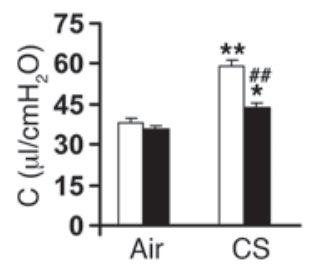

F

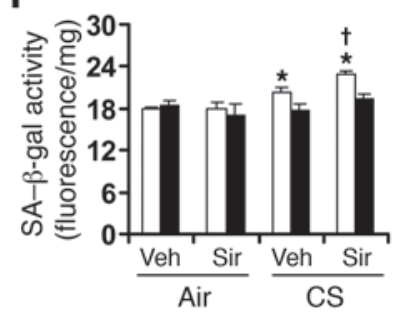

Figure 9

p21 deficiency ameliorates CS-induced airspace enlargement and lung function decline and protects against both CS- and sirtinol-induced increase in SA- $\beta$-gal activity. (A and B) CS exposure for 6 months led to airspace enlargement in WT mice, which was attenuated in $p 21^{-/-}$mice. (C) p21 deficiency protected against increased lung compliance induced by 6 months of CS exposure. (D) No alteration of $R_{L}$ was observed in either WT or $p 21^{-/-}$mice exposed to CS for 6 months. (E) Genetic ablation of $p 21$ attenuated 6 months of CS-mediated increase in SA- $\beta$-gal activity in mouse lung. (F) Sirtinol (Sir) treatment further increased SA- $\beta$-gal activity in lungs of WT mice, but not $P 21^{-/-}$mice, in response to 3 days of CS exposure. H\&E-stained images are representative of experiments from 3 separate mice. Original magnification, $\times 100$. Scale bar: $100 \mu \mathrm{m}$. SA- $\beta$-gal activity is expressed as 4-MU fluorescence normalized to protein content (see Methods). $n=3-4$ per group. ${ }^{*} P<0.05$, ${ }^{\star \star} P<0.01, \S P<0.001$ versus air; ${ }^{*} P<0.05,{ }^{\#} P<0.01$ versus $\mathrm{WT} ;{ }^{\dagger} P<0.05$ versus vehicle.

running, despite repeated contact with the electric grid. At this stage, each mouse was immediately returned to its home cage.

Oxygen saturation determination. A pulse oximeter (Starr Life Sciences) was used to measure blood arterial oxygen saturations in conscious mice (40, 86). Briefly, the pulse oximeter sensor clip was placed on the back of the mouse neck after depilation, and the mouse was put in the STARR-Dust cage until calm. The oxygen saturation was determined and collected using the MouseOx software (Starr Life Sciences).

Measurement of lung mechanics. Lung mechanical properties, including lung compliance and $\mathrm{R}_{\mathrm{L}}$, were determined as described previously (40). Briefly, the mouse was weighed, deeply anesthetized by i.p. injection of pentobarbital $(90 \mathrm{mg} / \mathrm{kg} \mathrm{BW})$ and pancuronium $(0.5 \mathrm{mg} / \mathrm{kg} \mathrm{BW})$, and tracheostomized. The trachea was cannulated, and the cannula was connected to a computer-controlled small animal ventilator (FlexiVent; SCIREQ). Estimated lung compliance, $\mathrm{R}_{\mathrm{L}}$, and $\mathrm{Rn}$ at $3 \mathrm{cmH}_{2} \mathrm{O}$ positive end-expiratory pressure were obtained by fitting a model to each impedance spectrum. The calibration procedure removed the impedance of the equipment and tracheal tube within this system.

$B A L$. Mice were injected with $100 \mathrm{mg} / \mathrm{kg} \mathrm{BW}$ pentobarbiturate (Abbott Laboratories) i.p. and sacrificed by exsanguination. The heart and lungs were removed en bloc, and the lungs were lavaged 3 times with $0.6 \mathrm{ml}$ of $0.9 \%$ sodium chloride, as described previously $(40,79)$. The lavaged fluid was centrifuged, and the cell-free supernatants were frozen at $-80^{\circ} \mathrm{C}$ for later analysis. The BAL cell pellet was resuspended in $1 \mathrm{ml}$ of $0.9 \%$ sodium chloride, and the total cell number was determined by counting on a hemocytometer. Differential cell counts (minimum of 400 cells per slide) were performed on cytospin-prepared slides (Thermo Shandon) stained with Diff-Quik (Dade Behring).

Lung morphometry. Mouse lungs (which had not been lavaged) were inflated with $1 \%$ low-melt agarose at a pressure of $25 \mathrm{~cm} \mathrm{H}_{2} \mathrm{O}$, then fixed with $4 \%$ neutral buffered PFA $(34,40)$. Fixed lung was dehydrated, embedded in paraffin, and sectioned into $4-\mu \mathrm{m}$ sections using a rotary microtome (MICROM International $\mathrm{GmbH}$ ). H\&E staining was performed on the lung midsagittal sections to determine Lm of airspace using MetaMorph software (Molecular Devices) (40). Ten randomly selected $\times 100$ fields per slide were photographed in a blinded manner, and the images were manually thresholded. The airway and vascular structures were eliminated from the analysis.

Preparation of whole cell lysate and nuclear protein. The preparation of whole cell lysate and nuclear protein from lung tissue and BAL cells were described previously (87). Briefly, lung tissue $(100 \mathrm{mg})$ was mechanically homogenized with $0.5 \mathrm{ml}$ of radioimmunoprecipitation assay (RIPA) buffer $(50 \mathrm{mmol} / 1$ Tris- $\mathrm{HCl}, 150 \mathrm{mmol} / 1 \mathrm{NaCl}, 1 \mathrm{mmol} / 1$ EDTA, $0.25 \%$ deoxycholate, $1 \mathrm{mmol} / 1 \mathrm{Na}_{3} \mathrm{VO}_{4}, 1 \mathrm{mmol} / \mathrm{l} \mathrm{NaF}, 1 \mathrm{mg} / 1$ leupeptin, $1 \mathrm{mg} / \mathrm{l}$ aprotinin, and $1 \mathrm{mmol} / \mathrm{PMSF}$ ), and the tissue homogenates were kept on ice for 45 minutes to allow total cell lysis. Similarly, the BAL cells were lysed with RIPA buffer for 30 minutes on ice, and then vortexed for 15 seconds. Following centrifugation at $13,000 \mathrm{~g}$ in an eppendorf tube for 5 minutes, the supernatant was collected as whole cell lysate. For isolation of nuclear proteins, lung tissue $(100 \mathrm{mg})$ was mechanically homogenized in $0.5 \mathrm{ml}$ of ice-cold buffer A (10 mM HEPES [pH 7.8], $10 \mathrm{mM} \mathrm{KCl,} 2 \mathrm{mM} \mathrm{MgCl}_{2}$, $1 \mathrm{mM}$ DTT, $0.1 \mathrm{M}$ EDTA, $0.2 \mathrm{mM} \mathrm{NaF}, 0.2 \mathrm{mM} \mathrm{Na}_{3} \mathrm{VO}_{4}, 1 \%$ [v/v] NP-40, 0.4 
A

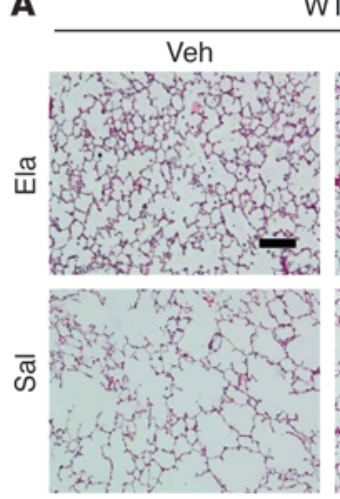

C

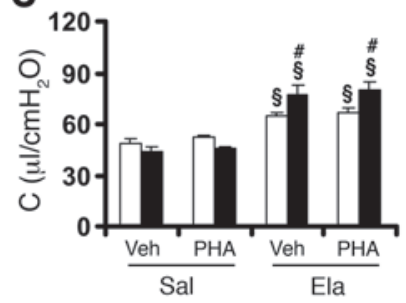

F

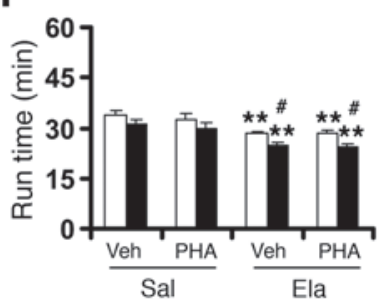

WT

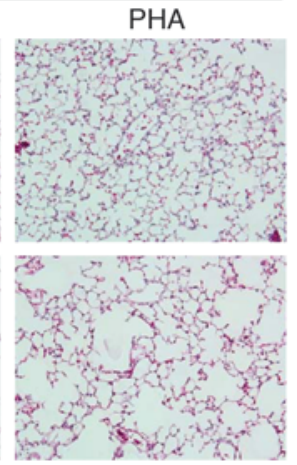

D

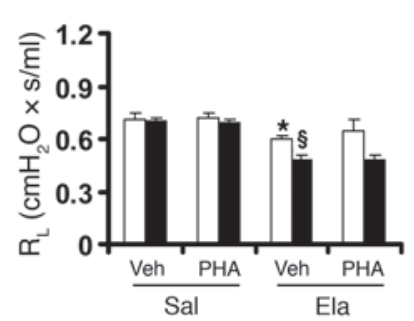

G

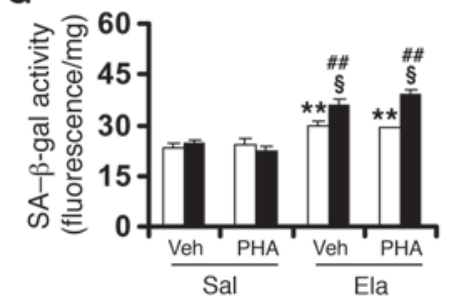

Sirt1 ${ }^{+/}$

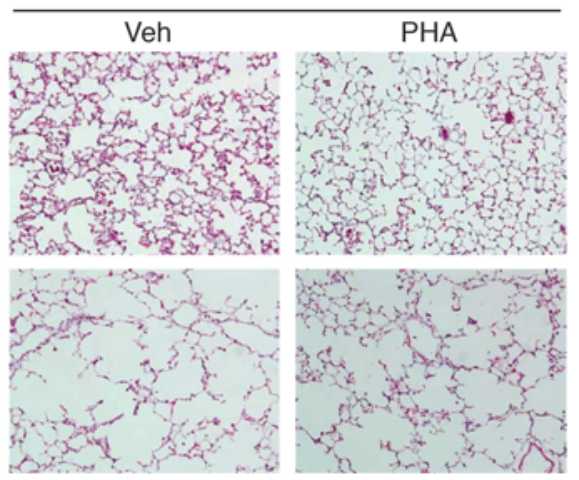

E

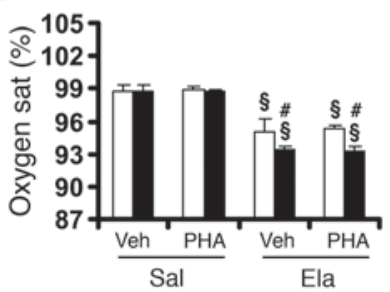

B

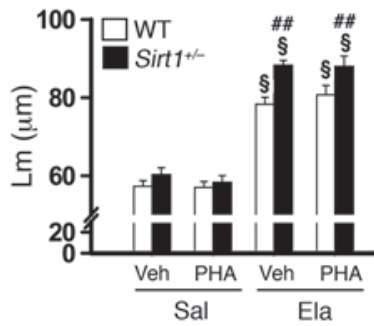

Figure 10

The IKK2 inhibitor PHA-408 does not influence elastase-induced emphysema or increase in SA- $\beta$-gal activity in lungs of either Sirt1+/- or WT mice. (A and B) Treatment with PHA-408 (PHA) did not alter elastase-induced increase in Lm of airspace in either Sirt1 1/- mice or WT littermates. (C and D) Lung compliance (C) or $R_{L}(\mathbf{D})$ was not affected by PHA-408 in either WT or Sirt1+- mice exposed to elastase. (E and F) Decreased arterial oxygen saturation (E) or running time (F) induced by elastase was not affected by PHA-408 treatment. (G) Elastase-induced increase in SA- $\beta$-gal activity was not altered by PHA-408. H\&E-stained images are representative of experiments from 3 separate mice. Original magnification, $\times 100$. Scale bar: $100 \mu \mathrm{m}$. SA- $\beta$-gal activity is expressed as 4-MU fluorescence normalized to protein content (see Methods). $n=3-4$ per group. ${ }^{*} P<0.05,{ }^{\star \star} P<0.01,{ }^{\S} P<0.001$ versus saline; ${ }^{\#} P<0.05,{ }^{\# \#} P<0.01$ versus vehicle.

$\mathrm{mM}$ PMSF, and $1 \mu \mathrm{g} / \mathrm{ml}$ leupeptin), and the homogenate was centrifuged at 2,000 $\mathrm{g}$ in a benchtop centrifuge for 30 seconds at $4^{\circ} \mathrm{C}$ to remove cellular debris. The supernatant was then transferred into a $1.7 \mathrm{ml}$ ice-cold eppendorf tube and further centrifuged for 30 seconds at $13,000 \mathrm{~g}$ at $4{ }^{\circ} \mathrm{C}$. The pellet was resuspended in $50 \mu \mathrm{l}$ of buffer $\mathrm{C}(50 \mathrm{mM}$ HEPES [ $\mathrm{pH} 7.8$ ], $50 \mathrm{mM}$ $\mathrm{KCl}, 300 \mathrm{mM} \mathrm{NaCl}, 0.1 \mathrm{M}$ EDTA, $1 \mathrm{mM}$ DTT, 10\% [v/v] glycerol, $0.2 \mathrm{mM}$ $\mathrm{NaF}, 0.2 \mathrm{mM} \mathrm{Na}_{3} \mathrm{VO}_{4}$, and $0.6 \mathrm{mM} \mathrm{PMSF}$ ) and placed on the rotating rocker in the cold room for 30 minutes. Following centrifugation at $13,000 \mathrm{~g}$ in an eppendorf tube for 5 minutes, the supernatant was collected as the nuclear extract and stored at $-80^{\circ} \mathrm{C}$ until use. Protein levels in samples were measured with a BCA kit (Pierce).

Immunoblot. Protein samples from lung homogenates and BAL cell lysates were separated on $6 \%-10 \%$ SDS-PAGE. The separated proteins were electroblotted onto nitrocellulose membranes (Amersham). The membranes were blocked for 1 hour at room temperature with 5\% BSA, and then probed with a 1:400-1:1000 diluted antibodies of anti-SIRT1, anti-p53, anti-acetylated RelA/p65 at K310 (Cell Signaling Technology), anti-p21, anti-p16, anti-p27, anti-RelA/p65, and anti-FOXO3 (Santa Cruz Biotechnology) antibodies to determine respective proteins. After 3 washing steps (10 minutes each), pro- tein levels were detected using secondary antibody (1:5,000 dilution in $2.5 \%$ BSA in PBS containing $0.1 \%$ Tween [v/v] 20 for 1 hour) linked to horseradish peroxidase (Dako), and bound complexes were detected using the ECL method (Perkin Elmer). Equal loading of the samples was determined by quantitation of proteins as well as by reprobing membranes for $\beta$-actin. Band density was calculated by densitometry analysis and expressed as fold change relative to corresponding loading control, $\beta$-actin.

Immunoprecipitation. Whole cell lysates were used for FOXO3 immunoprecipitation with an antibody against FOXO3 (1:40 dilution; Santa Cruz Biotechnology), which was added to $300 \mu \mathrm{g}$ of sample proteins in a final volume of $400 \mu \mathrm{l}$, and incubated for 1 hour. Protein- $\mathrm{A} / \mathrm{G}$ agarose beads (20 $\mu \mathrm{l}$; Santa Cruz Biotechnology) were added to each sample and kept overnight at $4{ }^{\circ} \mathrm{C}$ on a rotating rocker. The beads were washed 3 times and then resuspended in $40 \mu \mathrm{l}$ of RIPA buffer. For immunoblot, the immunoprecipitated $\mathrm{FOXO} 3$ agarose bead suspension was resolved by SDS-PAGE. IgG and beads only were used as negative controls. To assess FOXO3 acetylation and its interaction with SIRT1, the membranes of immunoprecipitated FOXO3 were blotted against anti-acetylated lysine or SIRT1 (Cell Signaling), respectively. 


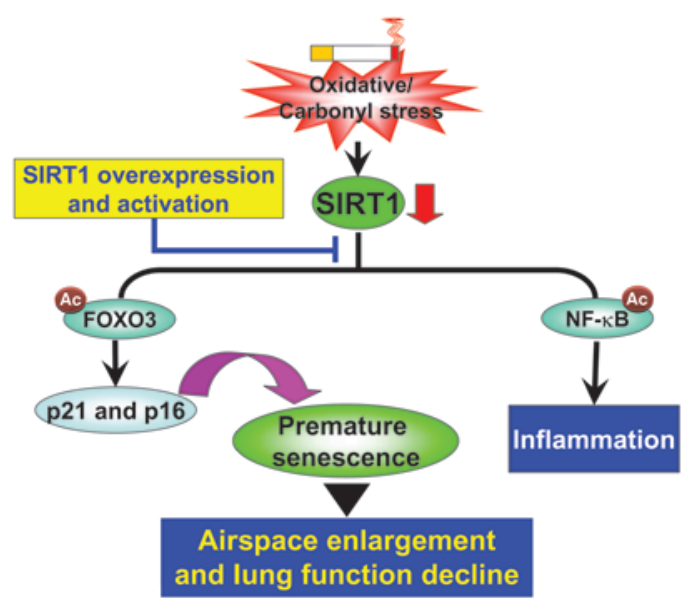

Figure 11

Role of the SIRT1/FOXO3 pathway in protecting against emphysema. Lung level of SIRT1 is reduced in response to CS or oxidative/carbonyl stress, which leads to acetylation and degradation of $\mathrm{FOXO} 3$ and culminates in stress-induced premature senescence. The senescence of lung cells is a contributing factor to airspace enlargement and emphysema. NF- $\mathrm{KB}$ is also acetylated and activated in response to CS exposure as a result of SIRT1 reduction. However, inhibition of $\mathrm{NF}-\mathrm{\kappa B}-$ dependent lung inflammation does not prevent the progression of airspace enlargement. SIRT1 activation by overexpression and pharmacological means protects the lungs against cellular senescence and emphysematous changes.

SIRT1 deacetylase activity assay. SIRT1 activity was assayed using a deacetylase colorimetric activity assay kit (Biomol International) according to the manufacturer's instructions (38). Briefly, SIRT1 was immunoprecipitated from whole lung homogenates (200 $\mu \mathrm{g}$ protein) in RIPA buffer. The Color de Lys substrate reagent and $\mathrm{NAD}^{+}$were added to the SIRT1-conjugated beads and incubated at $37^{\circ} \mathrm{C}$ for 80 minutes following the final washing. The substrate-SIRT1 mixture was then placed on a 96-well plate, and the Color de Lys developer reagent was added to the wells at $37^{\circ} \mathrm{C}$ for $20 \mathrm{~min}$ utes. The plate was then read at $405 \mathrm{~nm}$ using a spectrophotometer (Model 680 microplate reader; Bio-Rad).

SA- $\beta$-gal activity assay. SA- $\beta$-gal activity was quantitatively measured by the rate of conversion of 4-methylumbelliferyl- $\beta$-D-galactopyranoside (MUG) to the fluorescent hydrolysis product 4-methylumbelliferone (4-MU) at $\mathrm{pH} 6.0$, as described previously (88). Briefly, lung tissues were homogenized in the lysis buffer ( $5 \mathrm{mM}$ CHAPS, $40 \mathrm{mM}$ citric acid, $40 \mathrm{mM}$ sodium phosphate, $0.5 \mathrm{mM}$ benzamidine, and $0.25 \mathrm{mM}$ PMSF, $\mathrm{pH} 6.0$ ), and kept on ice for 1 hour. The lysates were centrifuged for 5 minutes at $12,000 \mathrm{~g}$, and the supernatant was mixed with $2 \times$ reaction buffer $(40 \mathrm{mM}$ citric acid, $40 \mathrm{mM}$ sodium phosphate, $300 \mathrm{mM} \mathrm{NaCl}, 10 \mathrm{mM} \beta$-mercaptoethanol, and $4 \mathrm{mM} \mathrm{MgCl}_{2}$ [pH 6.0] with $1.7 \mathrm{mM} \mathrm{MUG}$ ), which was placed into a $37^{\circ} \mathrm{C}$ water bath for 3 hours. Finally, $50 \mu \mathrm{l}$ of the reaction mix was added to $500 \mu \mathrm{l}$ of $400 \mathrm{mM}$ sodium carbonate stop solution ( $\mathrm{pH} 11.0$ ), which was read at $150 \mu \mathrm{l} /$ well in a 96 -well plate using a SpectrumMax M5 plate reader (Molecular Devices) with excitation at $360 \mathrm{~nm}$, emission at 465 $\mathrm{nm}, 40 \mu$ s integration, and gain held constant at 46 . Normalized SA- $\beta$-gal activity was expressed as observed fluorescence (rate of conversion of 4-methylumbelliferyl- $\beta$-d-galactopyranoside to $4-\mathrm{MU}$ ) divided by milligram total protein in the assay.

The OCT-embedded frozen lung tissues were sectioned at 6 - $\mu \mathrm{m}$ thickness and stained to determine SA- $\beta$-gal activity using a commercial kit (Cell Signaling Technology). Briefly, the lungs were fixed in $2 \%$ formal- dehyde containing $0.2 \%$ glutaraldehyde for 15 minutes and washed with PBS 2 times; subsequently, samples were incubated at $37^{\circ} \mathrm{C}$ for 24 hours in the staining solution $(1 \mathrm{mg} / \mathrm{ml} \mathrm{X}$-gal in dymethylformamide, $5 \mathrm{nM}$ potassium ferrocyanide, $5 \mathrm{nM}$ potassium ferricyanide, $40 \mathrm{mM}$ citric acid/sodium phosphate, $0.15 \mathrm{M} \mathrm{NaCl}$, and $2 \mathrm{mM} \mathrm{MgCl}_{2}, \mathrm{pH} 5.9$ ). The cells with blue color were considered SA- $\beta$-gal positive.

Clara cell isolation. The Clara cells were isolated from mouse lung as described previously (89). Briefly, the RV was cannulated and flushed with sterile PBS after anesthetizing the mice. The lungs were instilled with $1 \%$ low-melting temperature agarose $(0.5 \mathrm{ml})$, and kept on ice for 2 minutes. Then, $0.5 \mathrm{ml}$ bovine pancreatic trypsin (0.25\%; Sigma-Aldrich) in HBSS without $\mathrm{Ca}^{2+}$ and $\mathrm{Mg}^{2+}$ was instilled into the lung, which was incubated at $37^{\circ} \mathrm{C}$ for 10 minutes. The lung tissues were excised away from the large airways and cut into approximately $1-\mathrm{mm}^{3}$ pieces in DMEM containing $250 \mu \mathrm{g} / \mathrm{ml}$ DNAse I. The resulting suspension was filtered through 100and $40-\mu \mathrm{M}$ filters sequentially prior to the sedimentation by centrifugation at $200 \mathrm{~g}$ for 10 minutes. The cell pellet was resuspended in DMEM and washed 3 times through spinning at $32 \mathrm{~g}$ for 6 minutes at $10^{\circ} \mathrm{C}$. To remove alveolar macrophages and fibroblasts, the cells were plated in dishes precoated with mouse IgG (500 $\mu \mathrm{g} / \mathrm{ml}$; Sigma-Aldrich) for 1 hour, and the nonadherent cells were collected and regarded as the Clara cells by CC10 Clara cell-specific marker staining (see below).

Immunohistochemical staining. The deparaffinized and rehydrated lung sections were exposed to $3 \% \mathrm{H}_{2} \mathrm{O}_{2}$ in methanol for 30 minutes to quench endogenous peroxidase activity after antigen retrieval using the citrate buffer (0.01 M, pH 6.0). Nonspecific binding of antibodies to the tissue sections was blocked by incubating sections with $5 \%$ normal goat serum in PBS for 30 minutes. Lung tissue sections were incubated with primary SIRT1 (Millipore) or p21 (Abcam) antibody at a titer of 1:100 overnight at $4{ }^{\circ} \mathrm{C}$. After being washed, sections were incubated with secondary antibody biotinylated anti-rabbit Ig (DAKO) for 1 hour, and DAB (DAKO) was used as peroxidase substrate. The counterstaining with hematoxylin was then performed before examination under a light microscope.

Fluorescent staining. BAL cells and the isolated Clara cells $\left(2 \times 10^{4}\right.$ cells/ slide) were used to prepare the cytospin slides (500 $\mathrm{g}$ for 5 minutes), and fixed in 4\% PFA for 10 minutes. The cells and deparaffinized lung sections were then permeabilized for 10 minutes in $0.3 \%$ Triton X-100 in PBS, and blocked for 1 hour using 10\% normal goat serum. Samples were incubated with rabbit SIRT1 antibody (Millipore) alone or along with goat CC10 antibody (Santa Cruz Biotechnology) in a humidified chamber overnight; primary antibodies were detected with Alexa Fluor 594 goat anti-rabbit and Alexa Fluor 488 donkey anti-goat IgG (Invitrogen), respectively. The samples were then mounted with anti-fade DAPI fluoromount (Southern Biotech) and viewed under a fluorescence microscope.

Human samples. The lung tissue specimens from 27 subjects - 10 lifelong nonsmokers and 17 patients with COPD - were collected by the Department of Medicine and Pathology, Helsinki University Central Hospital (18, 51). The OCT-embedded frozen human lung tissues used for SA- $\beta$-gal staining were obtained from transplant donors and patients with COPD. COPD was defined according to the GOLD criteria $\left(\mathrm{FEV}_{1},<80 \%\right.$ of predicted; $\mathrm{FEV}_{1} / \mathrm{FVC},<70 \%$; bronchodilatation effect, $\left.<12 \%\right)$. None of the patients had suffered from acute exacerbation for 2 months. The clinical characteristics of the patients used were described in detail previously (18).

Statistics. Statistical analysis of significance was calculated by 1-way ANOVA for multigroup comparisons using STATVIEW. Results are shown as mean \pm SEM. A $P$ value less than 0.05 was considered statistically significant.

Study approval. All animal protocols described in this study were approved by the University Committee on Animal Research of the University of Rochester. The use of human tissue was approved by the ethics committee 
of the Helsinki University Central Hospital. All subjects, including nonsmokers and COPD patients, provided informed consent.

\section{Acknowledgments}

This study was supported by NIH grants 1R01HL085613, 1R01HL097751, and 1R01HL092842 (to I. Rahman); NIH grant R01HL81148 (to D.A. Dean); and NIEHS Environmental Health Science Center grant P30-ES01247. V.L. Kinnula was partly supported by a special governmental subsidy for healthy science research of the Helsinki University Central Hospital (HUCH EVO) and Finnish Antituberculosis Association Foundation. We thank Michael O'Reilly for providing the p21 knockout mice and Thomas J. Mariani for provid- ing the Cre recombinase transgenic mice from the CC10 promoter. We thank Suzanne E. Cook, Stephanie Uhrinek, and Gnanapragasam Arunachalam (University of Rochester) for technical assistance.

Received for publication July 22, 2011, and accepted in revised form March 7, 2012.

Address correspondence to: Irfan Rahman, Department of Environmental Medicine, University of Rochester Medical Center, Box 850, 601 Elmwood Avenue, Rochester, New York 14642, USA. Phone: 585.275.6911; Fax: 585.276.0239; E-mail: irfan_rahman@ urmc.rochester.edu.
1. MacNee W, Tuder RM. New paradigms in the pathogenesis of chronic obstructive pulmonary disease I. Proc Am Thorac Soc. 2009;6(6):527-531.

2. Karrasch S, Holz O, Jorres RA. Aging and induced senescence as factors in the pathogenesis of lung emphysema. Respir Med. 2008;102(9):1215-1230.

3. Tsuji T, Aoshiba K, Nagai A. Alveolar cell senescence in patients with pulmonary emphysema. Am J Respir Crit Care Med. 2006;174(8):886-893.

4. Han MK, et al. Chronic obstructive pulmonary disease phenotypes: the future of COPD. Am J Respir Crit Care Med. 2010;182(5):598-604.

5. Yao H, Rahman I. Current concepts on oxidative/ carbonyl stress, inflammation and epigenetics in pathogenesis of chronic obstructive pulmonary disease. Toxicol Appl Pharmacol. 2011;254(2):72-85.

6. Leibiger IB, Berggren PO. Sirt1: a metabolic master switch that modulates lifespan. Nat Med. 2006; 12(1):34-36.

7. Chung S, Yao H, Caito S, Hwang JW, Arunachalam G, Rahman I. Regulation of SIRT1 in cellular functions: role of polyphenols. Arch Biochem Biophys. 2010;501(1):79-90.

8. Donmez G, Guarente L. Aging and disease: connections to sirtuins. Aging Cell. 2010;9(2):285-290.

9. Zhang J, et al. The type III histone deacetylase Sirt1 is essential for maintenance of $\mathrm{T}$ cell tolerance in mice. J Clin Invest. 2009;119(10):3048-3058.

10. Yuan J, Pu M, Zhang Z, Lou Z. Histone H3-K56 acetylation is important for genomic stability in mammals. Cell Cycle. 2009;8(11):1747-1753.

11. Brunet A, et al. Stress-dependent regulation of FOXO transcription factors by the SIRT1 deacetylase. Science. 2004;303(5666):2011-2015.

12. Dang W, et al. Histone H4 lysine 16 acetylation regulates cellular lifespan. Nature. 2009; 459(7248):802-807.

13. Willcox BJ, et al. FOXO3A genotype is strongly associated with human longevity. Proc Natl Acad Sci US A. 2008;105(37):13987-13992.

14. Kyoung Kim H, et al. Down-regulation of a forkhead transcription factor, FOXO3a, accelerates cellular senescence in human dermal fibroblasts. J Gerontol A Biol Sci Med Sci. 2005;60(1):4-9.

15. Dentice $M$, et al. The FoxO3/type 2 deiodinase pathway is required for normal mouse myogenesis and muscle regeneration. J Clin Invest. 2010; 120(11):4021-4030.

16. Sengupta A, Molkentin JD, Paik JH, DePinho RA, Yutzey KE. FoxO transcription factors promote cardiomyocyte survival upon induction of oxidative stress. J Biol Chem. 2011;286(9):7468-7478.

17. Nakamaru Y, et al. A protein deacetylase SIRT1 is a negative regulator of metalloproteinase-9. FASEB J. 2009;23(9):2810-2819.

18. Rajendrasozhan S, Yang SR, Kinnula VL, Rahman I. SIRT1, an antiinflammatory and antiaging protein, is decreased in lungs of patients with chronic obstructive pulmonary disease. Am J Respir Crit Care Med. 2008;177(8):861-870.

19. Savale L, et al. Shortened telomeres in circulating leukocytes of patients with chronic obstructive pulmonary disease. Am J Respir Crit Care Med. 2009; 179(7):566-571.

20. Mui TS, et al. Telomere length and chronic obstructive pulmonary disease: evidence of accelerated aging. J Am Geriatr Soc. 2009;57(12):2372-2374.

21. Lambers $C$, et al. T cell senescence and contraction of $\mathrm{T}$ cell repertoire diversity in patients with chronic obstructive pulmonary disease. Clin Exp Immunol. 2009;155(3):466-475.

22. Nyunoya T, Monick MM, Klingelhutz A, Yarovinsky TO, Cagley JR, Hunninghake GW. Cigarette smoke induces cellular senescence. Am J Respir Cell Mol Biol. 2006;35(6):681-688.

23. Muller KC, et al. Lung fibroblasts from patients with emphysema show markers of senescence in vitro. Respir Res. 2006;7:32.

24. Tsuji T, Aoshiba K, Nagai A. Cigarette smoke induces senescence in alveolar epithelial cells. Am J Respir Cell Mol Biol. 2004;31(6):643-649.

25 . Hara $\mathrm{H}$, et al. Involvement of creatine kinase B in cigarette smoke-induced bronchial epithelial cell senescence. Am J Respir Cell Mol Biol. 2012;46(3):306-312.

26. McBurney MW, et al. The mammalian SIR2alpha protein has a role in embryogenesis and gametogenesis. Mol Cell Biol. 2003;23(1):38-54

27. Bordone L, et al. SIRT1 transgenic mice show phenotypes resembling calorie restriction. Aging Cell. 2007;6(6):759-767.

28. Oga T, Nishimura K, Tsukino M, Sato S, Hajiro $\mathrm{T}$, Mishima M. Exercise capacity deterioration in patients with COPD: longitudinal evaluation over 5 years. Chest. 2005;128(1):62-69.

29. Li H, Rajendran GK, Liu N, Ware C, Rubin BP, Gu Y. SirT1 modulates the estrogen-insulin-like growth factor-1 signaling for postnatal development of mammary gland in mice. Breast Cancer Res. 2007;9(1):R1.

30. Simon DM, et al. Epithelial cell PPAR[gamma] contributes to normal lung maturation. FASEB J. 2006;20(9):1507-1509.

31. Schug TT, et al. Myeloid deletion of SIRT1 induces inflammatory signaling in response to environmental stress. Mol Cell Biol. 2010;30(19):4712-4721.

32. Giannakou ME, Partridge L. The interaction between FOXO and SIRT1: tipping the balance towards survival. Trends Cell Biol. 2004;14(8):408-412.

33. Tsuji T, Aoshiba K, Nagai A. Alveolar cell senescence exacerbates pulmonary inflammation in patients with chronic obstructive pulmonary disease. Respiration. 2010;80(1):59-70.

34. Yao H, et al. Disruption of p21 attenuates lung inflammation induced by cigarette smoke, LPS, and fMLP in mice. Am J Respir Cell Mol Biol. 2008; 39(1):7-18.

35. Yeung F, et al. Modulation of NF-kappaB-dependent transcription and cell survival by the SIRT 1 deacetylase. EMBO J. 2004;23(12):2369-2380.

36. Di Stefano A, et al. Increased expression of nuclear factor-kappaB in bronchial biopsies from smokers and patients with COPD. Eur Respir J. 2002; 20(3):556-563
37. Yang SR, Wright J, Bauter M, Seweryniak K, Kode A, Rahman I. Sirtuin regulates cigarette smokeinduced proinflammatory mediator release via RelA/p65 NF-kappaB in macrophages in vitro and in rat lungs in vivo: implications for chronic inflammation and aging. Am J Physiol Lung Cell Mol Physiol. 2007;292(2):L567-L576.

38. Caito S, et al. SIRT1 is a redox-sensitive deacetylase that is post-translationally modified by oxidants and carbonyl stress. FASEB J. 2010;24(9):3145-3159.

39. Braidy N, Guillemin GJ, Mansour H, Chan-Ling T, Poljak A, Grant R. Age related changes in NAD+ metabolism oxidative stress and Sirt 1 activity in wistar rats. PLoS One. 2011;6(4):e19194.

40. Yao H, et al. Extracellular superoxide dismutase protects against pulmonary emphysema by attenuating oxidative fragmentation of ECM. Proc Natl Acad Sci U S A. 2010;107(35):15571-15576.

41. Vanoirbeek JA, et al. Noninvasive and invasive pulmonary function in mouse models of obstructive and restrictive respiratory diseases. Am J Respir Cell Mol Biol. 2010;42(1):96-104.

42. McDonough JE, et al. Small-airway obstruction and emphysema in chronic obstructive pulmonary disease. NEngl J Med. 2011;365(17):1567-1575.

43. Irvin CG, Bates JH. Measuring the lung function in the mouse: the challenge of size. Respir Res. 2003;4:4.

44. Rangasamy T, et al. Genetic ablation of Nrf2 enhances susceptibility to cigarette smoke-induced emphysema in mice. J Clin Invest. 2004;114(9):1248-1259.

45. Guerassimov A, et al. The development of emphysema in cigarette smoke-exposed mice is strain dependent. Am J Respir Crit Care Med. 2004;170(9):974-980.

46. Han W, Dong Z, Dimitropoulou C, Su Y. Hydrogen sulfide ameliorates tobacco smoke-induced oxidative stress and emphysema in mice. Antioxid Redox Signal. 2011;15(8):2121-2134.

47. Yoshida T, et al. Rtp801, a suppressor of mTOR signaling, is an essential mediator of cigarette smokeinduced pulmonary injury and emphysema. Nat Med. 2010;16(7):767-773.

48. Clauss M, et al. Lung endothelial monocyte-activating protein 2 is a mediator of cigarette smokeinduced emphysema in mice. J Clin Invest. 2011; 121(6):2470-2479.

49. Hegab AE, et al. Intranasal HGF administration ameliorates the physiologic and morphologic changes in lung emphysema. Mol Ther. 2008;16(8):1417-1426.

50. Iizuka T, et al. Nrf2-deficient mice are highly susceptible to cigarette smoke-induced emphysema. Genes Cells. 2005;10(12):1113-1125.

51 . Hwang JW, et al. FOXO3 deficiency leads to increased susceptibility to cigarette smoke-induced inflammation, airspace enlargement, and chronic obstructive pulmonary disease. J Immunol. 2011;187(2):987-998.

52. Aoshiba K, Nagai A. Senescence hypothesis for the pathogenetic mechanism of chronic obstructive pulmonary disease. Proc Am Thorac Soc. 2009; 6(7):596-601.

53. Palacios JA, Herranz D, De Bonis ML, Velasco S, Serrano $\mathrm{M}$, Blasco MA. SIRT1 contributes to telomere 
maintenance and augments global homologous recombination. J Cell Biol. 2010;191(7):1299-1313.

54. Alder JK, et al. Telomere length is a determinant of emphysema susceptibility. Am J Respir Crit Care Med. 2011;184(8):904-912

55. Koike $\mathrm{K}$, et al. Complete lack of vitamin C intake generates pulmonary emphysema in senescence marker protein-30 knockout mice. Am J Physiol Lung Cell Mol Physiol. 2010;298(6):L784-L792.

56. Afanas'ev I. Reactive oxygen species and age-related genes p66shc, Sirtuin, FOX03, and Klotho in senescence. Oxid Med Cell Longev. 2010;3(2):77-85.

57. Holloway KR, et al. SIRT1 regulates Dishevelled proteins and promotes transient and constitutive Wnt signaling. Proc Natl Acad Sci U S A. 2010; 107(20):9216-9221.

58. Guarani V, et al. Acetylation-dependent regulation of endothelial Notch signalling by the SIRT1 deacetylase. Nature. 2011;473(7346):234-238.

59. Sato $T$, et al. Senescence marker protein- 30 protects mice lungs from oxidative stress, aging, and smoking. Am J Respir Crit Care Med. 2006;174(5):530-537.

60. Suga T, et al. Disruption of the klotho gene causes pulmonary emphysema in mice. Defect in maintenance of pulmonary integrity during postnatal life. Am J Respir Cell Mol Biol. 2000;22(1):26-33.

61 . Alcendor RR, et al. Sirt 1 regulates aging and resistance to oxidative stress in the heart. Circ Res. 2007; 100(10):1512-1521.

62. Tanno M, et al. Induction of manganese superoxide dismutase by nuclear translocation and activation of SIRT1 promotes cell survival in chronic heart failure. J Biol Chem. 2010;285(11):8375-8382.

63. Kops GJ, et al. Forkhead transcription factor FOXO3a protects quiescent cells from oxidative stress. Nature. 2002;419(6904):316-321.

64 . He W, et al. Sirt 1 activation protects the mouse renal medulla from oxidative injury. J Clin Invest. 2010; 120(4):1056-1068

65. You H, Yamamoto K, Mak TW. Regulation of transactivation-independent proapoptotic activity of p53 by FOXO3a. Proc Natl Acad Sci U S A. 2006; 103(24):9051-9056.

66. You H, et al. p53-dependent inhibition of FKHRL1 in response to DNA damage through protein kinase SGK1. Proc Natl Acad Sci U S A. 2004; 101(39):14057-14062.

67. Petrache I, et al. Ceramide upregulation causes pulmonary cell apoptosis and emphysema-like disease in mice. Nat Med. 2005;11(5):491-498.

68. Arunachalam G, Yao H, Sundar IK, Caito S, Rahman I. SIRT1 regulates oxidant- and cigarette smoke-induced eNOS acetylation in endothelial cells: Role of resveratrol. Biochem Biophys Res Commun. 2010;393(1):66-72.

69. Hwang JW, et al. Cigarette smoke-induced autophagy is regulated by SIRT1-PARP-1-dependent mechanism: implication in pathogenesis of COPD. Arch Biochem Biophys. 2010;500(2):203-209.

70. Sequeira J, et al. sirt1-null mice develop an autoimmune-like condition. Exp Cell Res. 2008; 314(16):3069-3074.

71. Rahman I, Kinnula VL, Gorbunova V, Yao H. SIRT1 as a therapeutic target in inflammaging of the pulmonary disease [published online ahead of print December 8, 2011]. Prev Med. doi:10.1016/ j.ypmed.2011.11.014.

72. Freund A, Orjalo AV, Desprez PY, Campisi J. Inflammatory networks during cellular senescence: causes and consequences. Trends Mol Med. 2010; 16(5):238-246.

73. Acosta JC, et al. Chemokine signaling via the CXCR2 receptor reinforces senescence. Cell. 2008; 133(6):1006-1018.

74. Xue W, et al. Senescence and tumour clearance is triggered by $\mathrm{p} 53$ restoration in murine liver carcinomas. Nature. 2007;445(7128):656-660.

75. Foronjy $\mathrm{R}$, et al. Transgenic expression of matrix metalloproteinase- 9 causes adult-onset emphysema in mice associated with the loss of alveolar elastin. Am J Physiol Lung Cell Mol Physiol. 2008; 294(6):L1149-L1157.

76. Lanone $\mathrm{S}$, et al. Overlapping and enzyme-specific contributions of matrix metalloproteinases- 9 and -12 in IL-13-induced inflammation and remodeling. J Clin Invest. 2002;110(4):463-474.

77. Westphal CH, Dipp MA, Guarente L. A therapeutic role for sirtuins in diseases of aging? Trends Biochem Sci. 2007;32(12):555-560

78. Castrillon DH, Miao L, Kollipara R, Horner JW,
DePinho RA. Suppression of ovarian follicle activation in mice by the transcription factor Foxo3a. Science. 2003;301(5630):215-218.

79. Yao H, et al. Cigarette smoke-mediated inflammatory and oxidative responses are strain-dependent in mice. Am J Physiol Lung Cell Mol Physiol. 2008;294(6):L1174-L1186.

80. Foronjy RF, et al. Superoxide dismutase expression attenuates cigarette smoke- or elastase-generated emphysema in mice. Am J Respir Crit Care Med. 2006; 173(6):623-631.

81. Kim SR, et al. Involvement of sirtuin 1 in airway inflammation and hyperresponsiveness of allergic airway disease. J Allergy Clin Immunol. 2010; 125(2):449-460.

82. Milne JC, et al. Small molecule activators of SIRT1 as therapeutics for the treatment of type 2 diabetes. Nature. 2007;450(7170):712-716

83. Ota H, et al. Sirt 1 inhibitor, Sirtinol, induces senescence-like growth arrest with attenuated Ras-MAPK signaling in human cancer cells. Oncogene. 2006; 25(2):176-185.

84. Rajendrasozhan S, Hwang JW, Yao H, Kishore N, Rahman I. Anti-inflammatory effect of a selective IkappaB kinase-beta inhibitor in rat lung in response to LPS and cigarette smoke. Pulm Pharmacol Ther. 2010;23(3):172-181.

85. Massett MP, Berk BC. Strain-dependent differences in responses to exercise training in inbred and hybrid mice. Am J Physiol Regul Integr Comp Physiol. 2005; 288(4):R1006-R1013.

86. Verhoeven D, Teijaro JR, Farber DL. Pulse-oximetry accurately predicts lung pathology and the immune response during influenza infection. Virology. 2009;390(2):151-156.

87. Yao $\mathrm{H}$, et al. Protein kinase $\mathrm{C}$ zeta mediates cigarette smoke/aldehyde- and lipopolysaccharideinduced lung inflammation and histone modifications. J Biol Chem. 2010;285(8):5405-5416.

88. Gary RK, Kindell SM. Quantitative assay of senescenceassociated beta-galactosidase activity in mammalian cell extracts. Anal Biochem. 2005;343(2):329-334.

89. Atkinson JJ, Adair-Kirk TL, Kelley DG, Demello D, Senior RM. Clara cell adhesion and migration to extracellular matrix. Respir Res. 2008;9:1. 